\title{
Comparative analysis of the Photorhabdus luminescens and the Yersinia enterocolitica genomes: uncovering candidate genes involved in insect pathogenicity Ralf Heermann*1 and Thilo M Fuchs*2
}

Address: ${ }^{1}$ Ludwig-Maximilians-Universität München, Department Biologie I, Bereich Mikrobiologie, Maria-Ward-Str. 1a, D-80638 München, Germany and 2Zentralinstitut für Ernährungs- und Lebensmittelforschung (ZIEL), Abteilung Mikrobiologie, Technische Universität München, Weihenstephaner Berg 3, D-85354 Freising, Germany

Email: Ralf Heermann* - heermann@lmu.de; Thilo M Fuchs* - thilo.fuchs@wzw.tum.de

* Corresponding authors

Published: 25 January 2008

BMC Genomics 2008, 9:40 doi:10.1 186/147/-2164-9-40
Received: 28 September 2007

Accepted: 25 January 2008

This article is available from: http://www.biomedcentral.com/I47/-2/64/9/40

(C) 2008 Heermann and Fuchs; licensee BioMed Central Ltd.

This is an Open Access article distributed under the terms of the Creative Commons Attribution License (http://creativecommons.org/licenses/by/2.0), which permits unrestricted use, distribution, and reproduction in any medium, provided the original work is properly cited.

\begin{abstract}
Background: Photorhabdus luminescens and Yersinia enterocolitica are both enteric bacteria which are associated with insects. P. luminescens lives in symbiosis with soil nematodes and is highly pathogenic towards insects but not to humans. In contrast, $Y$. enterocolitica is widely found in the environment and mainly known to cause gastroenteritis in men, but has only recently been shown to be also toxic for insects. It is expected that both pathogens share an overlap of genetic determinants that play a role within the insect host.
\end{abstract}

Results: A selective genome comparison was applied. Proteins belonging to the class of twocomponent regulatory systems, quorum sensing, universal stress proteins, and c-di-GMP signalling have been analysed. The interorganismic synopsis of selected regulatory systems uncovered common and distinct signalling mechanisms of both pathogens used for perception of signals within the insect host. Particularly, a new class of LuxR-like regulators was identified, which might be involved in detecting insect-specific molecules. In addition, the genetic overlap unravelled a twocomponent system that is unique for the genera Photorhabdus and Yersinia and is therefore suggested to play a major role in the pathogen-insect relationship. Our analysis also highlights factors of both pathogens that are expressed at low temperatures as encountered in insects in contrast to higher (body) temperature, providing evidence that temperature is a yet underinvestigated environmental signal for bacterial adaptation to various hosts. Common degradative metabolic pathways are described that might be used to explore nutrients within the insect gut or hemolymph, thus enabling the proliferation of $P$. luminescens and $Y$. enterocolitica in their invertebrate hosts. A strikingly higher number of genes encoding insecticidal toxins and other virulence factors in $P$. luminescens compared to $Y$. enterocolitica correlates with the higher virulence of $P$. luminescens towards insects, and suggests a putative broader insect host spectrum of this pathogen.

Conclusion: A set of factors shared by the two pathogens was identified including those that are involved in the host infection process, in persistence within the insect, or in host exploitation. Some of them might have been selected during the association with insects and then adapted to pathogenesis in mammalian hosts. 


\section{Background}

Pathogenicity as well as symbiosis plays a key role in the interaction of bacteria with their hosts including invertebrates. Despite the relevance of this relationship for the evolution of bacterial pathogenicity, few studies have addressed this subject at the genomic level. We therefore decided to perform a comparative study of the genomes of Photorhabdus luminescens and Yersinia enterocolitica. The former bacterium is a representative of pathogens highly virulent towards insects, but apathogenic against men. $Y$. enterocolitica, an example of a primarily human pathogen, also confers toxicity to insects, but is less toxic towards these hosts than P. luminescens.

Members of the genus Yersinia are primarily considered as mammalian pathogens. However, Y. pestis, a blood-borne pathogen and the etiological agent of human plague, has long been known to be transmitted by insects, specifically by rat fleas. Y. enterocolitica strains have been isolated from flies that are assumed to play an important role in food contamination by this pathogen [1-3], and Y. pseudotuberculosis strains were recovered from fly larvae isolated in the wild [4]. More recent data strongly support the idea that yersiniae are capable to interact with insects. Loci encoding the insecticidal toxin complexes (Tc) have been identified in the genomes of $Y$. pestis KIM [5], $Y$. pseudotuberculosis [6], and Y. enterocolitica [7]. Y. pseudotuberculosis, in contrast to $Y$. pestis, has been shown to be orally toxic to flea [8]. This toxicity revealed to be independent of $t c$ genes, suggesting that loss of one or more insect gut toxins is a critical step in the change of the Y. pestis lifestyle compared with the Y. pseudotuberculosis and thus in evolution of flea-borne transmission [8]. While $Y$. enterocolitica and $Y$. pseudotuberculosis have diverged within the last 200 million years, Y. pestis has emerged from Y. pseudotuberculosis only 1,500-20,000 years ago [9]. Bacterial lysates both of Y. enterocolitica and Y. pseudotuberculosis are toxic for Manduca sexta neonates, and significant levels of natively or heterologously expressed toxins were observed in both species at $15^{\circ} \mathrm{C}$, but not at mammalian body temperature $[7,10]$. Furthermore, $Y$. pseudotuberculosis and $Y$. enterocolitica have been demonstrated to adhere to and invade cultivated insect cells [10]. Thus, the interaction of $Y$. enterocolitica with insects is an important link in the ecological range of bacteria-host interactions extending from entomopathogenic to humanpathogenic bacteria.

In contrast, Photorhabdus luminescens is predominantly an insect pathogenic enterobacterium which maintains a mutualistic interaction with heterorhabditid nematodes, and can infect a wide range of insects $[11,12]$. Interestingly, another Photorhabdus species, P. asymbiotica, has been described as a human pathogen. It was isolated from human clinical specimens where the cells caused locally invasive soft tissue infections $[13,14]$. It is assumed that these strains are associated with spiders, because spider bites where attended with Photorhabdus human infections [15]. However, bacteria of the species P. luminescens are exclusively known to be associated with nematodes and insects. Generally, the bacteria colonise the gut of the infective juvenile stage of the nematode Heterorhabditis bacteriophora. Upon entering an insect host, the nematodes release the bacteria by regurgiation directly into the insect hemocoel, the open circulatory system of the insect. Once inside the hemocoel, the bacteria replicate rapidly and establish a lethal septemica in the host by the production of virulence factors such as the insecticidal toxin complexes that kill the insect within 48 hours. Bioconversion of the insect's body by $P$. luminescens produces a rich food source for the bacteria as well as for the nematodes. Nematode reproduction is supported by the bacteria, probably by providing essential nutrients that are required for efficient nematode proliferation [16]. Further properties of $P$. luminescens are the production of many antimicrobial substances to defend the insect cadaver from bacterial competitors, and glowing due to bacterial luciferase production. When the insect cadaver is depleted, the nematodes and bacteria reassociate and emerge from the carcass in search of a new insect host (Fig. 1, right circle)[17,18]. Photorhabdus species exist in two forms, designated as primary and secondary phenotypic colony variants, which differ in morphological and physiological traits. Primary variants are found to produce extracellular protease, extracellular lipase, intracellular protein crystals CipA and CipB, antibiotics, and are bioluminescent. Secondary variants lack protease, lipase and antibiotic activity, and bioluminescence is strongly decreased. They also differ in colony morphology, pigmentation, dye adsorption, metabolism, and the ability to support growth and reproduction of the nematodes. It is assumed that primary variants correspond to the nematode-associated form, and secondary variants to the insect-associated form of the bacteria $[19,20]$. Therefore, $P$. luminescens serves as an ideal model to study the switch from a symbiotic state with nematodes to one in which the bacterium is pathogenic to insects $[21,22]$.

In the following comparative genome analysis, we examined the extent to which $P$. luminescens and $Y$. enterocolitica share factors that are probably attributed to insect association. We identified genes and the corresponding proteins involved in signalling, regulation, pathogenicity, as well as in metabolism, and suggest their possible function during colonization and infection of non-mammals. The results obtained not only improve our understanding of the biology of both pathogens, but also reveal some implications on the evolution of invertebrate and vertebrate virulence factors. 


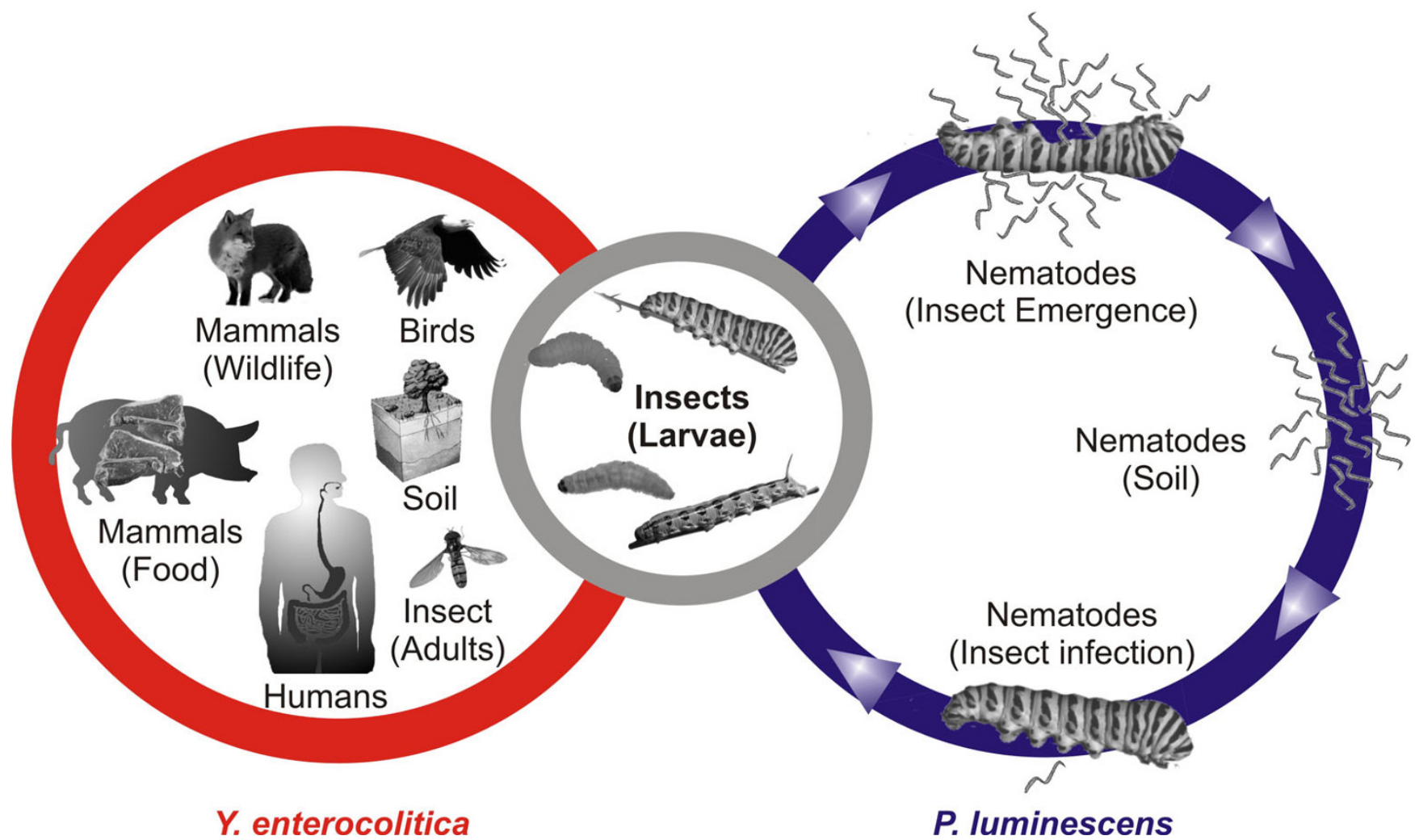

Figure I

The life cycles of $\boldsymbol{P}$. luminescens and $\boldsymbol{Y}$. enterocolitica. Right: $P$. luminescens is an endosymbiont of the nematode species $H$. bacteriophora, both living in a highly specific symbiosis. When the nematodes once have infected the insect larvae, they release the highly entomopathogenic bacteria directly into the hemocoel, resulting in a rapid death of the host. The carcass is a rich food source allowing proliferation of both the nematodes and the bacteria. When the cadaver is depleted, nematodes and bacteria reassociate, emerge from the insect, and scan the soil for new victims. Left: $Y$. enterocolitica is found in the soil, in water, in meat or within the gastrointestinal tract of birds [130] or mammals, but is primarily considered as a human pathogen. Middle: $Y$. enterocolitica are able to infect mammals, but are also toxic to insects which are assumed to play a role in evolution and transmission of this bacterium. In contrast to $P$. luminescens which is infectious only towards insect larvae, $Y$. enterocolitica has also been isolated from adult insects [I]. The life cycle stage shared by $P$. luminescens and $Y$. enterocolitica corresponds to a common pool of virulence factors as shown by genome dissection presented here.

\section{Results and Discussion}

The genomes of $P$. luminescens ssp. laumondii TT01 and $Y$. enterocolitica 8081 have completely been sequenced. The genome of the latter strain has a size of $\sim 4.6 \mathrm{Mbp}$ and encodes 4037 putative proteins [23]. Its genome size is exceeded by the $\sim 5.7 \mathrm{Mbp}$ genome of P. luminescens encoding 4839 putative proteins [24]. To uncover candidate genes which are involved in insect pathogenicity, a total of 424 ( $P$. luminescens) and 386 (Y. enterocolitica) genes and proteins predicted to belong to one of the functional categories described in the text were analysed for their presence or absence in both organisms, and for their degree of similarity. House-keeping genes and genes of unknown function were not considered. The set of shared genes or proteins, respectively, indicates mechanisms of regulation, virulence and metabolic pathways similar for both pathogens, and moreover unraveled novel candidate genes/proteins which presumably are involved in insect association and/or pathogenicity. Proteins which are solely present in either one of the organisms suggest a distinct function of these factors, or different strategies followed by the two pathogens during their life cycles.

\section{Sensing, signalling, and regulation}

Bacteria have evolved several regulation mechanisms to ensure a proper answer to changing environments. Upon entering their insect hosts, $P$. luminescens and $Y$. enterocolitica are challenged by varying and detrimental surrounding conditions which they have to sense and adapt to for further persistence. In addition, both pathogens must be capable to withstand the insect's immune response. In the following chapter we compare sensing and regulating mechanisms of the two insect-associated organisms, $P$. luminescens and Y. enterocolitica, thus identifying strategies 
which might be important for insect colonization and pathogenicity.

\section{Two-component signal transduction}

To sense their environment and to react rapidly to changing surrounding conditions, bacteria have evolved so called two-component systems (TCSs) [25] which have been found to be involved in the control of virulence or symbiosis, in metabolite utilization, and also in the adaptation to various stress factors [26]. A basic TCS consists of two proteins, a sensor histidine kinase and a response regulator performing a His-Asp phosphotransfer. The consisting domains or proteins can also be organized as more complex systems using a His-Asp-His-Asp phosphorelay. The number of TCSs ranges from zero in Mycoplasma genitalium to 80 in Syncheocystes spp. [25,27]. Eighteen of these TCSs are present in P. luminescens, and 28 in Y. enterocolitica, of which 17 are shared by both organisms (Fig. 2 , depicted in grey). The additional set of eleven TCSs in $Y$. enterocolitica (Fig. 2, shown in red) might reflect the high number of different environments this pathogen is exposed to during its life cycle, namely soil, water and invertebrates as well as mammalian hosts. In contrast, $P$. luminescens cells are primarily restricted to symbiosis with the nematode species $H$. bacteriophora and the insect larvae as hosts, thus encountering a more homeostatic milieu. Among the eleven TCSs of Y. enterocolitica not shared by $P$. luminescens are duplicates of the $\mathrm{CitA} / \mathrm{CitB}$ system (YE2505/YE2506 and YE2654/YE2655) and of the LytS/LytR system (YE1228/YE1227 and YE4014/YE4015). The principal biological reason for this redundancy remains unclear. Interestingly, one TCS (Plu0102/Plu103 and YE4185/YE4186) is unique for the genera Photorhab$d u s$ and Yersinia. Both sensor kinases Plu0102 and YE4185 are of moderate similarity (31.5\% identity, $48.5 \%$ homology). They are anchored to the membrane with one transmembrane domain, and have a large periplasmic sensing domain which is proposed to bind a specific ligand. Therefore, Plu0102 and YE4185 are interesting candidates for unravelling invertebrate-specific signals. The putative target genes of Plu0102/Plu0103 and Ye4185/Ye4186, plu0104 and ye4187, respectively, are homologues and encode putative secreted proteins which might act in a similar, yet unknown manner.

All TCSs present in both organisms are depicted in grey in Fig. 2, and include PhoP/PhoQ, and AstS/AstR (BvgS/ BvgR) which have been identified to be involved in virulence [28]. The role of PhoP/PhoQ in regulating virulence gene expression has been characterized mainly in Salmonella species, but has also been shown, in addition to three other TCSs, to be important for virulence of $Y$. pseudotuberculosis $[29,30]$. In P. luminescens, this TCS controls the expression of the pbgPE operon which is involved in lipid A modification and thus plays a role in colonization and infection of the invertebrate hosts [18,31]. Furthermore, PhoP has also been found to be important for virulence of $Y$. pestis [32], but its function in Y. enterocolitica during its insect-associated phase remains hypothetical. The AstS/ AstR TCS is required for the correct timing of phase variant switching in P. luminescens [28]. BvgS/BvgR is the TCS of $Y$. enterocolitica that corresponds to AstS/AstR. Because $Y$. enterocolitica is not known to switch to another phenotypic variant, the possible role in virulence regulation still remains to be elucidated. Both $Y$. enterocolitica and $P$. luminescens produce the $\mathrm{KdpD} / \mathrm{KdpE}$ system that regulates $\mathrm{K}^{+}$ homeostasis and osmotic stress. It has recently been found that the Kdp-system of $P$. luminescens is important for insect pathogenicity (S. E. Reynolds and N. R. Waterfield, University of Bath, UK, personal communication). Therefore, the $\mathrm{KdpD} / \mathrm{KdpE}$ system is also a further candidate system which might be involved in the regulation of insecticidal activity of $Y$. enterocolitica.

The only TCS of $P$. luminescens absent in $Y$. enterocolitica is TctE/TctD (Fig. 2, marked in blue), which, however, is found in the genomes of $Y$. intermedia and $Y$. frederiksenii. Beside these microorganisms, TctE/TctD homologues controlling the transport of tricarboxylic acid (see section "Tricarboxylate utilization") are present in the genera Salmonella, Burkholderia, Agrobacterium, Bordetella, Collinsella, Xylella, Xanthomonas, and Pseudomonas, particularly $P$. entomophila, all of which are found in association with eukaryotes.

To summarize, the comparison of the P. luminescens and the Y. enterocolitica TCSs reveals a basal set of signal sensing mechanisms which are used by both organisms. Whether the stimulons or regulons which are regulated by these sets of TCSs are also similar remains to be examined. In comparison to $P$. luminescens, $Y$. enterocolitica uses an expanded set of TCSs, possibly to adapt to its various hosts (Fig. 1).

\section{Quorum sensing-like gene regulation}

Regulation by AHL-LuxR-like receptors

Virulence, bioluminescence, mutualism, antibiotic production and biofilm formation are often regulated by LuxI/LuxR quorum sensing systems in Gram-negative bacteria. They produce membrane diffusible signalling molecules, acyl homoserine lactones (AHLs), which are sensed by the receptor/regulator LuxR when exceeding a threshold concentration. These AHLs are produced by an autoinductor synthase named LuxI. Upon autoinductorbinding, the receptor LuxR binds to the promoter/operator regions of the target genes or operons, resulting in the regulation of gene expression in response to the cell number [33]. Y. enterocolitica possesses a typical quorum sensing pair of homologues, YenI/YenR (YE1600/ YE1599), and it has recently been shown that swimming 


\section{environmental stimuli}

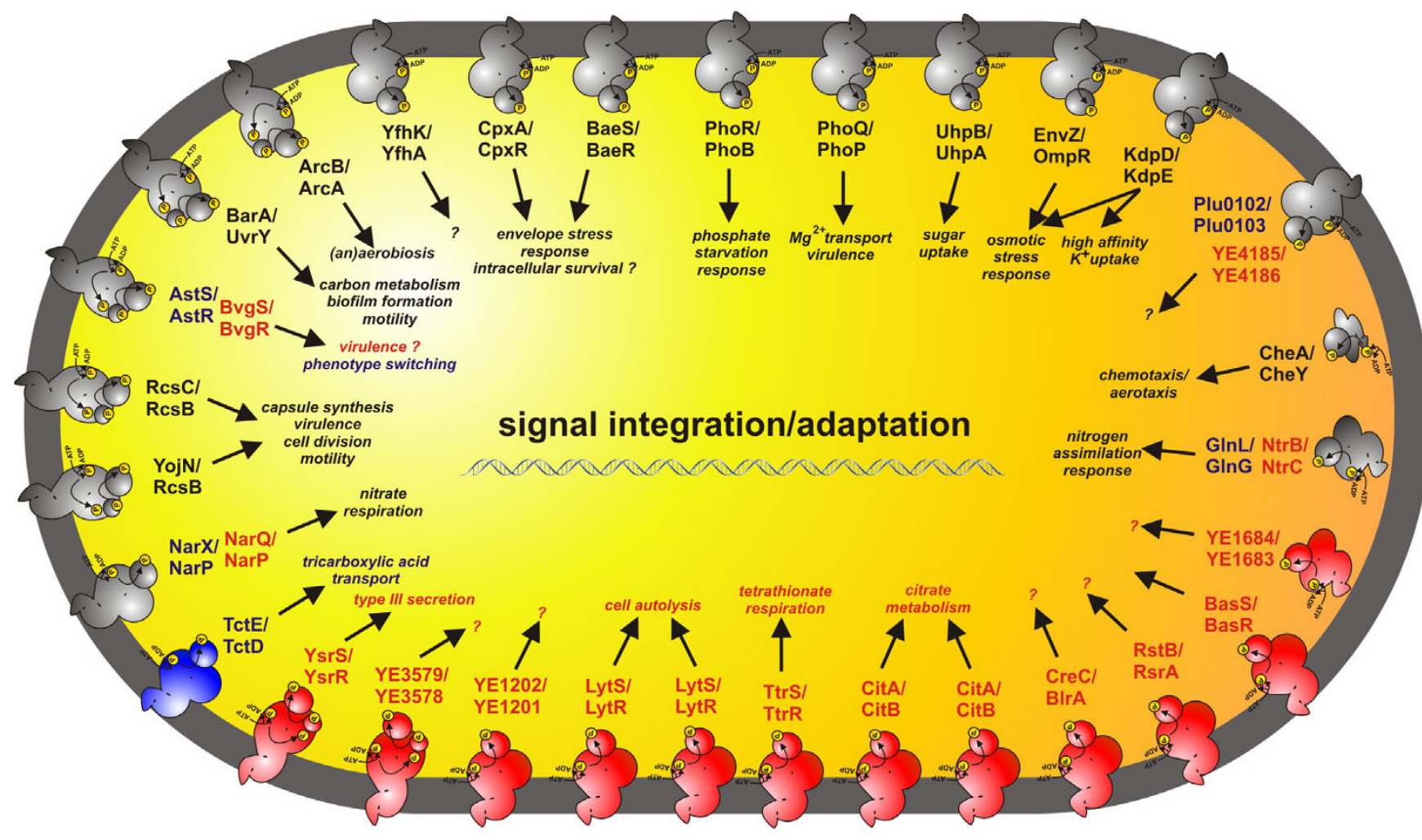

Y. enterocolitica and $P$. luminescens systems

Y. enterocolitica system

P. luminescens system

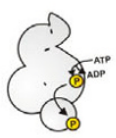

"His-Asp"

two-component system

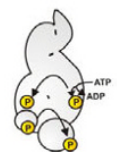

"His-Asp-His-Asp"

phosphorelay system

\section{Figure 2}

Two-component systems in P. luminescens and $Y$. enterocolitica. 18 TCSs are present in P. luminescens, and 28 TCSs in $Y$. enterocolitica. Both organisms share 17 of these systems (grey colour). One is singular to $P$. luminescens (coloured in blue), but I I to Y. enterocolitica (red colour). Basic TCSs (His-Asp phosphotransfer) and complex phosphorelay systems (His-Asp-His-Asp phosphorelay) are distinguished by different drawings. The 17 systems shared by the two pathogens, and also present in other (enteric) bacteria, are CPXAR and BaeSR (Envelope stress, [I3I]), CheAYW (motility, [I 32]), PhoRB (Phosphate starvation, [133]), UhpBA (Sugar uptake, [I34]), ArcBA (aerob/anaerob respiration, [ 135]), BarA/UvrY (carbon metabolism, motility, biofilm formation, [ I36]), RcsC/RcsD (capsular synthesis, virulence, [I37]), KdpD/KdpE (K+-limitation, osmotic stress, [I38]),

EnvZ/OmpR (osmotic stress, [139]), NtrB/NtrC and GlnL/GInG (nitrogen assimilation, [140]), PhoQ/PhoP (Mg2+ sensing, virulence, [I4I]), BvgSR/AstSR (virulence, phenotypic switching, [28, I42]), RcsC/RcsB and YojN/RcsB (capsule synthesis, cell division, motility, virulence, [143, 144]), and YfhK/YfhA, a system of unknown function. Furthermore, a TCS exists in both organisms which is unique for the genera Photorhabdus and Yersinia and cannot be found with a comparable homology/identity degree in any other yet known organism (Plu0I02/Plu0I03 and YE4I85/YE4I86). The II systems which are present in Y. enterocolitica, but not in P. luminescens, are YsrS/YsrR (activation of a Yersinia specific type-III secretion system, [87]), LytS/LytR (cell autolysis, [145]), CitA/CitB (citrate metabolism, [146]), TtrS/TtrR (tetrathionate respiration, [99]), and six systems of unknown function (YE3579/YE3578, YEI 202/YEI20I, YEI684/YEI683, CreC/BIrA, RstB/RstA, and BasS/BasR). 
and swarming motility is regulated by 3-oxo-C6-AHL and C6-AHL, which are synthesized by YenI [34]. In Y. pestis, the production of YspI and YspR, the homologues of YenI and YenR, is induced at $26^{\circ} \mathrm{C}$ (Table 1). Moreover, we identified a second AHL-LuxR regulator, YE1026, which lacks a separate AHL synthase (Fig. 3). It is not known if this receptor also binds the AHLs produced by YenI. In the genome of $P$. luminescens, two genes encoding putative AHL-LuxR-like receptors, plu0320 and plu4562, but no luxI genes are present (Fig. 3 ). This suggests that $P$. luminescens does not produce its own AHL signalling molecule, but might be able to sense those produced by other bacteria and therefore to detect mixed microbial communities as demonstrated for Salmonella enterica and Escherichia coli [35-37]. A similar function in Y. enterocolitica might be provided by YE1026. It is interesting to note that Sodalis glossinidius strain morsitans, an endosymbiont of the tse tse fly Glossina morsitans morsitans [38], also has two pontential AHL-LuxR receptors, SG1740 and SG0285, but no luxI homologue (Fig. 3). Instead of producing AHLs to regulate quorum dependent genes, a common strategy of insect-colonizing bacteria might be the detection of AHLs as a signal for the presence of other bacteria such as those colonizing the insect intestinal tract or living in soil.

\section{Regulation by Al-2}

Beside AHL, other putative quorum sensing signalling molecules have been identified. One of them is autoinductor 2 (AI-2), furanosyl borate diester, which is synthesized by the luxS product $[39,40]$ of which homologues are present in P. luminescens and Y. enterocolitica (plu1253, ye0839). It has been shown that the luxS pathway negatively controls the expression of genes for carbapenem antibiotic biosynthesis in P. luminescens [41]. Overall, more than $300 \mathrm{AI}-2$ regulated genes involved in regulation, metabolic activity, stress response and pathogenicity are known in P. luminescens [42]. For example, the expression of $t c d A 1$ and $t c c C 1$ encoding subunits of the insecticidal toxin complexes and the production of $m c f 2$ encoding the "Makes caterpillar floppy" toxin was identified to be luxS dependent. The $\Delta l u x S$ mutant also showed decreased expression of virulence factors such as the cytotoxic protein $\mathrm{CcdB}$, the hemolysin secretion protein HlyD (Plu0635), and the toxin ABC transporter subunits RtxD/ RtxB. Homologues of these proteins are present in Y. enterocolitica (see chapter 2 ), suggesting their possible regulation by AI- 2 also in this bacterium. Furthermore, the $P$. luminescens luxS-negative strain exhibited decreased biofilm formation, increased type IV/V pilus-dependent twitching motility, and attenuated virulence against insect larvae [42]. Taken together, a similar and AI-2 dependent mechanism for the regulation of insect colonization and insect pathogenicity might be used by both organisms. Whether they sense self-produced or external AI-2, or a combination of both, indicating a quorum sensing mech- anism or a regulation similar to AHL as described above, remains to be elucidated.

\section{Regulation by PAS_4/LuxR-like receptors}

In P. luminescens, the amount of luxR-like genes is overrepresented with 39 copies in the genome. 35 of these potential LuxR-like receptors exhibit PAS_4 signal binding domains instead of an AHL-binding domain, and two have a signalling domain with a yet unidentified motif (Fig. 3). Most of the genes are located in two large gene clusters (plu0918-0925 and plu2001-2019). Interestingly, eleven of those LuxR-like receptors are present in Y. enterocolitica of which five are located in a cluster (ye00350039). Nine of these have a so-called PAS_4 signal binding domains of yet unknown function. It is interesting to note that there is only one bacterium else, the insect colonizing $S$. glossinidius, whose genome also carries a series of unclustered genes coding for PAS_4/LuxR-like receptors, indicating that this kind of receptors plays a role during insect infection. PAS-domains have been suspected to act as insect juvenile hormone $(\mathrm{JH})$ receptors in the fruit fly Drosophila melanogaster $[43,44]$. The methoprene-tolerant gene (met, also called Resistance to Juvenile Hormone Rst1JH) of D. melanogaster encodes a helix-loop-helix transcriptional regulator combined with a PAS_3 domain [45]. Met has been shown to bind JH at physiological concentrations and is therefore suspected to act as a JH receptor $[46,47]$. Therefore, the potential PAS_4/LuxR-like receptors of $P$. luminescens, $Y$. enterocolitica, and $S$. glossinidius might sense JH or other eukaryotic hormones of the insect to adapt their gene expression to the insect host. The high number of 35 highly homologous receptor proteins in $P$. luminescens might be the reason for the wide insect host spectrum this pathogen is capable to infect. Although Y. enterocolitica protein extracts confer toxicity against $M$. sexta larvae [7], its host spectrum still remains to be defined. The difference in the number of the uncommon LuxR-like receptors (35 in P. luminescens, nine in $Y$. enterocolitica) gives rise to speculations that the insect host spectrum is constricted for Y. enterocolitica compared with P. luminescens. This hypothesis is underlined by the fact that not more than five PAS_4/LuxR-like receptors are present in $S$. glossinidius for which only one insect host has been reported.

\section{Regulation by uncommon LuxR-like receptors}

LuxR-like receptors in $Y$. enterocolitica with a yet unidentified signalling binding-site are YE2705 and YE3014, both of which are also present in Y. pestis (YPO2955 and YPO2593) and in S. glossinidius (SGP1_007, SG1174, SG1480, and SG1698), but not in P. luminescens (Fig. 3). It might be possible that signalling molecules of mammals and hormones of adult insects are sensed via these receptors by $Y$. enterocolitica and $S$. glossinidius, respectively, hosts which $P$. luminescens does not specifically 
Table I: Low-temperature induced genes and proteins and their putative function during the bacterial lifestage in insects. The differential expression was observed in $(1,2,8,9,10,12) Y$. enterocolitica $[7,78,87,94,147,148],(3,4,7) Y$. pestis $[149-15 I],(5) Y$. ruckeri [I52], (I I) Y. pseudotuberculosis [153] and (6) P. luminescens [I54].

\begin{tabular}{|c|c|c|c|c|c|c|}
\hline Class & Name & Function & Y. enterocolitica & P. luminescens & $\begin{array}{l}\text { Distribution among } \\
\text { bacterial genera }\end{array}$ & $\begin{array}{l}\text { Possible role in insect } \\
\text { gut/hemolymph }\end{array}$ \\
\hline \multirow[t]{7}{*}{$\begin{array}{l}\text { Substrate } \\
\text { transport }\end{array}$} & gltP/dctA (I) & $\begin{array}{l}\text { glutamate-aspartate } \\
\text { symport/transport of } \\
\text { C4- dicarboxylates } \\
\text { across the membrane }\end{array}$ & $0310(\mathrm{gltP}) / 4067(\mathrm{dct} A)$ & dctA (Plu3205) & ubiquitous & $\begin{array}{l}\text { uptake of peptides following } \\
\text { protease activity }\end{array}$ \\
\hline & $-(I)$ & permease & YE3697 & Plu459I & ubiquitous & unknown \\
\hline & $\operatorname{uhpABC}(1)$ & $\begin{array}{l}\text { hexose phosphate } \\
\text { transport }\end{array}$ & YE4089-4087 & Plu08I5-08I3 & ubiquitous & $\begin{array}{l}\text { exploitation of carbon } \\
\text { sources }\end{array}$ \\
\hline & $\operatorname{mgtC}(I)$ & $\begin{array}{l}\mathrm{Mg}^{2+} \text { transport ATPase } \\
\text { protein }\end{array}$ & YE2586 & Plu I 843 & ubiquitous & $\begin{array}{l}\text { virulence factor in } \\
\text { Salmonella }\end{array}$ \\
\hline & hemHFRS $(3,4)$ & hemin storage & YE248I-2484 & no homologue & ubiquitous & storage of excess hemin \\
\hline & irpl/irp2 (7) & $\begin{array}{l}\text { yersiniabactin } \\
\text { biosynthesis }\end{array}$ & YE2617/YE2618 & Plu2320/Plu232I & ubiquitous & iron acquisition \\
\hline & fepG (5) & $\begin{array}{l}\text { iron-siderophore } \\
\text { transport }\end{array}$ & YE3620 & Plu4625 & ubiquitous & iron acquisition \\
\hline \multirow{7}{*}{$\begin{array}{l}\text { Membrane } \\
\text { proteins }\end{array}$} & $-(1)$ & unknown & YEI324 & no homologue & ubiquitous & unknown \\
\hline & ompN homologue (I) & pore formation & YE2463 & Plu I75I & ubiquitous & osmolarity \\
\hline & $\operatorname{crcB}(I)$ & unknown & YE0964 & Plu I 290 & ubiquitous & unknown \\
\hline & $-(1)$ & unknown & YE2063 & no homologue & $\begin{array}{l}\text { Yersinia, Burkholderia, } \\
\text { Pseudomonas }\end{array}$ & unknown \\
\hline & $-(1)$ & $\begin{array}{l}\text { hypothetical membrane } \\
\text { protein }\end{array}$ & YE2063 & no homologue & $\begin{array}{l}\text { Yersinia, Burkholderia, } \\
\text { Pseudomonas, }\end{array}$ & unknown \\
\hline & $r b(9)$ & $\begin{array}{l}\text { synthesis of LPS O } \\
\text { antigen }\end{array}$ & YE3072-3087 & $\begin{array}{l}\text { Plu48I7-48I9, } \\
\text { Plu4824, Plu483। }\end{array}$ & ubiquitous & $\begin{array}{l}\text { blocking the access of bile } \\
\text { salts and complement to the } \\
\text { outer membrane }\end{array}$ \\
\hline & $-(I)$ & putative lipoprotein & YE2793 & no homologue & species-specific & unknown \\
\hline \multirow[t]{4}{*}{$\begin{array}{l}\text { Substrate } \\
\text { utilization }\end{array}$} & urease $(1,3,10)$ & urea amidohydolase & YE095I-0958 & $\begin{array}{l}\text { Plu217I-2177; } \\
\text { transporter missing }\end{array}$ & ubiquitous & $\begin{array}{l}\mathrm{pH} \text { adaptation, ammoniak } \\
\text { degradation }\end{array}$ \\
\hline & hutH (I) & histidine ammonia-lyase & YE302I/YE4094 & Plu3192 & ubiquitous & histidine utilization \\
\hline & prtA (6) & alkaline metalloprotease & YE4052 & Plu0655 & $\begin{array}{l}\text { Yersinia, Serratia, } \\
\text { Pseudomonas, Erwinia }\end{array}$ & bioconversion \\
\hline & $g \lg B(I)$ & $\begin{array}{l}\text { I,4-a glucan branching } \\
\text { enzyme }\end{array}$ & YE40I3 & no homologue & ubiquitous & $\begin{array}{l}\text { storage of surplus primary } \\
\text { carbohydrates }\end{array}$ \\
\hline \multirow[t]{5}{*}{ Regulation } & $\operatorname{arc} A B(I)$ & $\begin{array}{l}\text { TCS controlling the } \\
\text { response to respiratory } \\
\text { conditions }\end{array}$ & YE0595 & Plu0562 & ubiquitous & $\begin{array}{l}\text { (virulence) regulation during } \\
\text { anaerobic growth }\end{array}$ \\
\hline & $-(1)$ & $\begin{array}{l}\text { putative transcription } \\
\text { regulatory protein }\end{array}$ & YEI436 & Plu2862 & Yersinia & unknown \\
\hline & $-(I)$ & $\begin{array}{l}\text { EAL domain; } \\
\text { hypothetical }\end{array}$ & YE4063 & no homologue & $\begin{array}{l}\text { Yersinia, Shigella, } \\
\text { Escherichia }\end{array}$ & $\begin{array}{l}\text { regulation of virulence via c- } \\
\text { di-GMP }\end{array}$ \\
\hline & $-(1)$ & $\begin{array}{l}\text { EAL domain; } \\
\text { hypothetical }\end{array}$ & YEI324 & no homologue & $\begin{array}{l}\text { Yersinia, Shigella, } \\
\text { Escherichia, Vibrio }\end{array}$ & $\begin{array}{l}\text { regulation of virulence via c- } \\
\text { di-GMP }\end{array}$ \\
\hline & $\begin{array}{l}\text { yenl/yenR (yspl/yspR) } \\
\text { (3) }\end{array}$ & $\begin{array}{l}\text { N-acylhomoserine } \\
\text { lactone synthase Yenl/ } \\
\text { transcriptional regulator } \\
\text { YenR }\end{array}$ & YEI600/YEI599 & no homologue & $\begin{array}{l}\text { Sodalis, Serratia, Erwinia, } \\
\text { Aeromonas, } \\
\text { Pectobacterium, } \\
\text { Pseudomonas, } \\
\text { Agrobacterium, }\end{array}$ & $\begin{array}{l}\text { quorum sensing } \\
\text { contributing to the } \\
\text { regulation of virulence gene } \\
\text { expression }\end{array}$ \\
\hline \multirow[t]{9}{*}{$\begin{array}{l}\text { Virulence } \\
\text { factors }\end{array}$} & $\operatorname{srfA}(\mathrm{I})$ & $\begin{array}{l}\text { putative virulence factor, } \\
\text { ssrAB activated in } S . \\
\text { typhimurium }\end{array}$ & YE2057 & no homologue & $\begin{array}{l}\text { Yersinia, Salmonella, } \\
\text { Pseudomonas, } \\
\text { Enterobacter }\end{array}$ & unknown \\
\hline & fhaC (I) & hemolysin secretion & YE0480 & no homologue & $\begin{array}{l}\text { Yersinia, Burkholderia, } \\
\text { Pseudomonas, Bordetella, } \\
\text { Haemophilus }\end{array}$ & $\begin{array}{l}\text { cytolytic effect on } \\
\text { immunocytes and hemolytic } \\
\text { effect on blood cells }\end{array}$ \\
\hline & yst (2) & heat-stable enterotoxin & not annotated & no homologue & Yersinia & $\begin{array}{l}\text { release of nutrients from } \\
\text { gut cells }\end{array}$ \\
\hline & $\begin{array}{l}\text { tcdA, } t c d B \text { and } t c c C- \\
\text { like elements }(I)\end{array}$ & $\begin{array}{l}\text { insecticidal toxin } \\
\text { complex }\end{array}$ & tc-PAl ${ }^{Y e}$ & numerous loci & $\begin{array}{l}\text { Yersinia, Xenorhabdus, } \\
\text { Serratia }\end{array}$ & $\begin{array}{l}\text { cytotoxic activity against } \\
\text { insect tissue }\end{array}$ \\
\hline & $p h I A / B(5)$ & hemolysin secretion & YE2407/YE2408 & Plu03।6/Plu03।7 & ubiquitous & $\begin{array}{l}\text { cytolytic effect on } \\
\text { immunocytes and hemolytic } \\
\text { effect on blood cells }\end{array}$ \\
\hline & invE (II) & adhesion/invasion & YE3547 & no homologue & ubiquitous & colonization of insect gut \\
\hline & ysa (I2) & T3SS & see Fig. 5 & see Fig. 5 & $\begin{array}{l}\text { Yersinia, Burkholderia, } \\
\text { Erwinia, Xanthomonas, } \\
\text { Salmonella }\end{array}$ & colonization of insect gut \\
\hline & fle $A B C$ etc.(I) & flagellar genes & Flag-I genes & Flag-I genes & ubiquitous & motility \\
\hline & yplA (8) & Phospholipase & YEI005 & Plu3370 & $\begin{array}{l}\text { Yersinia, Serratia, } \\
\text { Xanthomonas }\end{array}$ & $\begin{array}{l}\text { survival within the insect } \\
\text { host }\end{array}$ \\
\hline
\end{tabular}




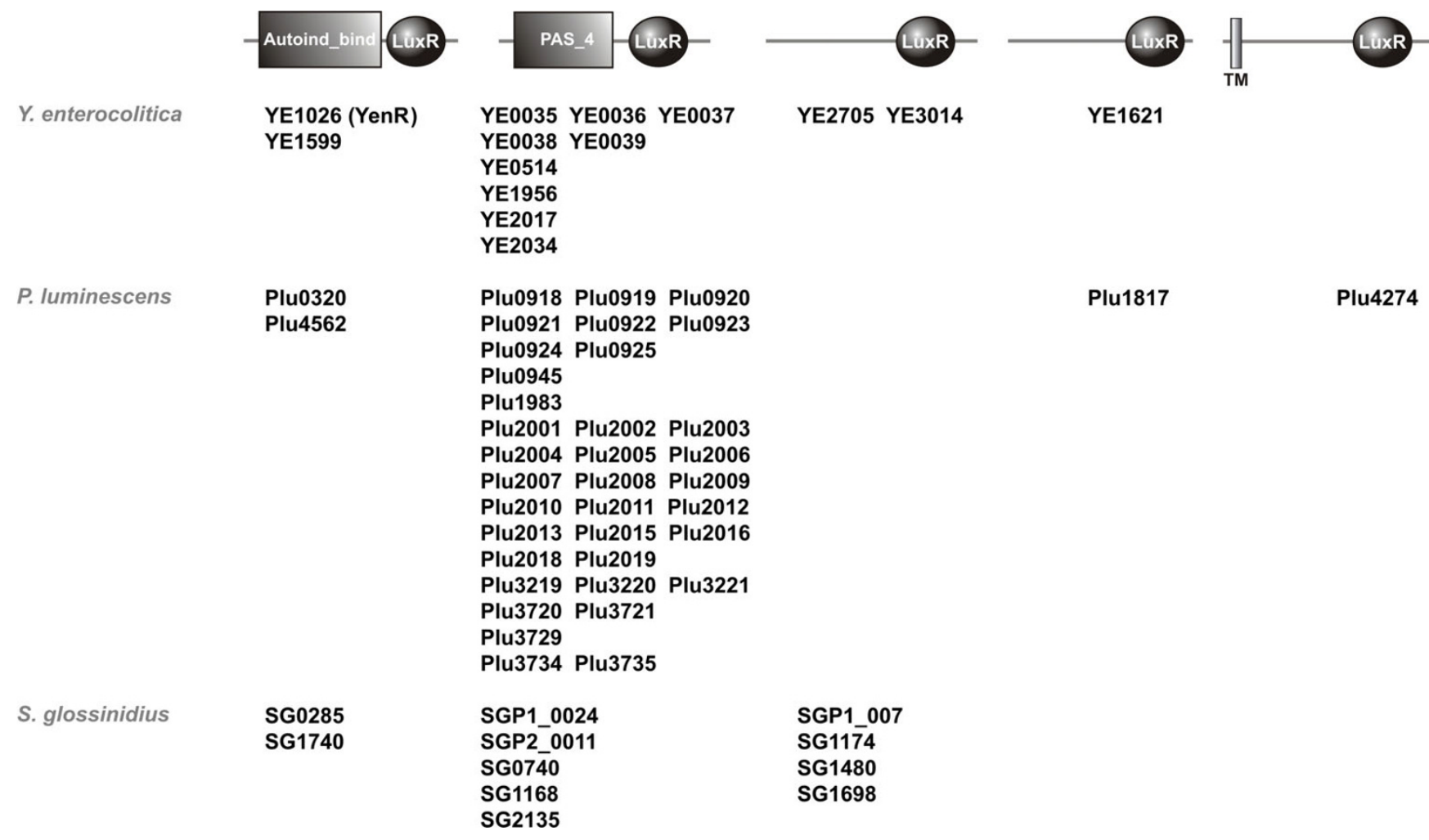

Figure 3

LuxR-like receptors in $P$. luminescens, $Y$. enterocolitica, and $S$. glossinidius. The five types of different LuxR-like receptors and their homologues in these three organisms are shown (see text for details). The "HTH_LuxR" motif (SMART0042I) is indicated by a circle, the "autoinductor-binding"-domain (PFAM03472) and the "PAS_4"-domain (PFAM08448) by boxes. TM: transmembrane domain.

interact with during its life cycle. In $P$. luminescens, two LuxR-like receptors with a yet unidentified signalling binding site are present, Plu4274 and Plu1817, the latter of which is shared by Y. enterocolitica (YE1621), but not by S. glossinidius.

\section{Universal stress proteins}

Universal stress proteins (Usp) are small soluble proteins found in bacteria, archaea and plants. The production of these proteins is induced upon global stress conditions such as nutrient starvation, heat stress, osmotic stress, oxidative stress, or the presence of toxic compounds. The protein family is divided into the UspA subfamily and the UspFG subfamily. The functional mechanism of these
Usp proteins is not known [48]. Because P. luminescens and $Y$. enterocolitica are exposed to those stresses upon infecting and colonizing the insect host, we compared their set of Usp proteins (Table 2). Both genomes share an UspA-like (Plu0121 and YE4050) and an UspE-like (Plu2178 and YE2076) homologue. In E. coli, the sequence motif of Usp proteins is not highly conserved: UspA and UspC show a sequence identity of $37 \%$ and a homology of $57 \%$, for example. In contrast, the UspA and the UspE homologues of $P$. luminescens and $Y$. enterocolitica are nearly similar, indicating that an identical stress response is regulated by these proteins. Homologues of these proteins are also present in $P$. aeruginosa, namely PA4352 and PA3309, a tandem-type Usp protein and a

Table 2: Universal Stress Proteins (Usp) in P. luminescens and $Y$. enterocolitica

\begin{tabular}{cccc}
\hline Name & Y. enterocolitica & P. luminescens & Coherence with insect association \\
\hline UspA & YE4050 & Plu012I & infection, colonization, anaerobiosis? switch to pathogenicity \\
UspE & YE2076 & Plu2 I78 & infection, colonization, anaerobiosis? \\
UspC & YE2583 & no homologue & $?$ \\
UspG & no homologue & Plu2030, Plu2032 & $?$ \\
\hline
\end{tabular}


UspA-like protein, respectively. They are essential for survival under anaerobic growth and therefore biofilm formation, a situation cells are exposed to when colonizing the cystic fibrosis lung in hosts $[49,50]$. The Usp homologues of $P$. luminescens and $Y$. enterocolitica might also be important during infection of the insect host.

In $P$. luminescens, expression of UspA has been shown to be under control of the AstS/AstR TCS, which is important for the correct timing of phase variant switching [28]. It is discussed that the AstS/AstR-system prevents or delays phenotypic variation by protecting the cell from stress [18]. Because Y. enterocolitica produces the corresponding TCS BvgS/BvgR, but is not known to switch to another phenotypic variant, the possible role of UspA in global regulation still remains to be elucidated. Phenotypic variation and thus the switch between mutualism and pathogenicity in P. luminescens is proposed to be regulated by a Ner-like and a HexA-like regulator that repress primary variant specific genes in the stage of the secondary variant [17]. Therefore, UspA might have a global importance in $P$. luminescens notifying stress and transmitting signals for HexA [18]. In Y. enterocolitica, the transcriptional repressor RovM (YE1343) is similar to HexA of P. luminescens $(61 \%$ identity and 75\% homology), and has only recently been shown to control cell invasion, virulence and motility in Y. pseudotuberculosis, Y. pestis and Y. enterocolitica [51-53]. This fact suggests a similar UspA-dependent regulatory mechanism used by the two bacteria compared here.

$P$. luminescens, but not $Y$. enterocolitica, produces two members of the UspFG family, the UspG homologues Plu2030 and Plu2032 (Tab. 2), indicating a global stress response induced by those Usp proteins that is different in both organisms. It is known that UspG of E. coli interacts with the chaperonin GroEL [54], which promotes the correct folding of many cytosolic proteins [55]. A GroEL homologue is present in P. luminescens (Plu4134) which the $P$. luminescens UspG homologues might interact with. In contrast to $P$. luminescens, $Y$. enterocolitica encodes another member of the UspA subfamily, the UspC homologue YE2583 (Tab. 2), which is not present in P. luminescens. Therefore, an UspC mediated stress response is not assumed to play a major role in insect pathogenicity.

Summarizing, the set of the shared and different Usp proteins reveals a partially similar and a partially different (fine)-regulation of the global stress response modules in $P$. luminescens and $Y$. enterocolitica. This pattern corresponds to the overlapping life cycles of both pathogens (Fig. 1). The UspA and the UspE homologues are predicted here to be relevant for insect infection, whereas UspC is assumed be more important for Y. enterocolitica in other environments/hosts. The two UspG homologues might constitute a set of Usp proteins that play a specific role in P. luminescens infection or in symbiosis with the nematode host.

\section{Regulation via c-di-GMP as a second messenger}

Cyclic diguanylate (c-di-GMP) is a bacterial second messenger that activates biofilm formation while inhibiting motility, thus regulating the switch between a planktonic and a sessile lifestyle. In addition to phenotypes that affect virulence properties indirectly, c-di-GMP can also directly regulate virulence factors $[56,57]$. Proteins containing a so-called GGDEF domain are responsible for the synthesis of c-di-GMP, and those with a so-called EAL domain for its degradation. The expression and activity of those GGDEF and EAL domain containing proteins is regulated by factors with a PilZ domain that binds c-di-GMP. The PilZ domain is found as a stand-alone domain or in combination with GGDEF, EAL and other domains, thus assumed to function also as an allosteric domain to control other regulatory enzymes [58,59]. In Y. enterocolitica, we identified 22 putative proteins containing GGDEF and EAL domains. Eleven of these proteins solely contain a GGDEF-domain and six solely an EAL-domain, and both domains are found in tandem in five proteins. The protein AdrA (YE3010, GGDEF domain) is annotated as a putative diguanylate cyclase, YE2278 (GGDEF+EAL) as a putative phosphodiesterase, YE3818 (GGDEF) as a putative regulator, and YE3806 (GGDEF+EAL) as a putative exported protein. All other GGDEF and EAL domain-containing proteins are of unknown function. Furthermore, two proteins with PilZ domain exist in Y. enterocolitica, namely YE3197 and BcsA (YE4074), a putative cellulose synthase. Cellulose synthesis in bacteria has been identified to be important for the protection from chemical or mechanical stress by forming a hydrophobic extracellular matrix [60]. The expression of two of those EAL-domain containing proteins, YE4063 and YE1324, is induced at low temperature (Tab. 1). These two factors might therefore be important for insect colonization instead for virulence against mammals. The presence of c-di-GMP mediated regulation in $Y$. enterocolitica is therefore suggested to play a central role in switching from biofilm formation to the human as well as to the insect environment. P. luminescens contains no protein with GGDEF, EAL or PilZ domain. This phenomenon is quite surprising, because with few exceptions such as Helicobacter pylori, nearly all pathogenic bacteria use c-di-GMP as a second messenger. It has been reported that $P$. luminescens forms biofilms in vitro, and that a luxS-deficient mutant unable to synthesize the quorum-sensing inducer AI- 2 showed a decreased biofilm formation [42]. The lack of these protein domains in P. luminescens reveals that c-di-GMP signalling plays a major role in pathogenic bacteria when colonizing a mammalian host, and a minor for invertebrate colonization of entomopathogenic or entomoinfecting bacteria. 


\section{Virulence factors}

So-called offensive virulence factors actively contribute to a successful infection by colonization of and toxicity towards the host organism. We compared both genomes with respect to genes encoding toxins, adhesins or invasines that are common to both pathogens. All virulence factors described in the following are summarized in Fig. 4.

\section{Toxins}

\section{Insecticidal toxins}

The insecticidal toxin complex (Tc) proteins were first purified from $P$. luminescens [61]. Tc homologues have also been described to be present in Yersinia spp. and in other insect-associated bacteria such as Serratia ento- mophila and Xenorhabdus nematophilus [62,63]. The respective genes encoding four high molecular weight toxin complexes are termed $t c a, t c b, t c c$ and $t c d$. Further experiments supported the hypothesis that TccC-like proteins might act as universal activators of, or chaperons for, different toxin proteins, while Tca-like and Tcd-like proteins contribute predominantly to the oral toxicity of bacterial supernatants [17]. It is speculated that the Tc toxins are active against different tissues within individual hosts, namely Tcb against hemocytes and Tcd and Tca against cells of the insect gut. In Y. enterocolitica, the insecticidal toxin genes are located on a distinct genomic island termed $t c$-PAI ${ }^{Y e}$ of $21 \mathrm{~kb}$, and are low-temperature induced [7]. Similar islands in which regulatory genes are followed by three tca genes, phage-related genes and one

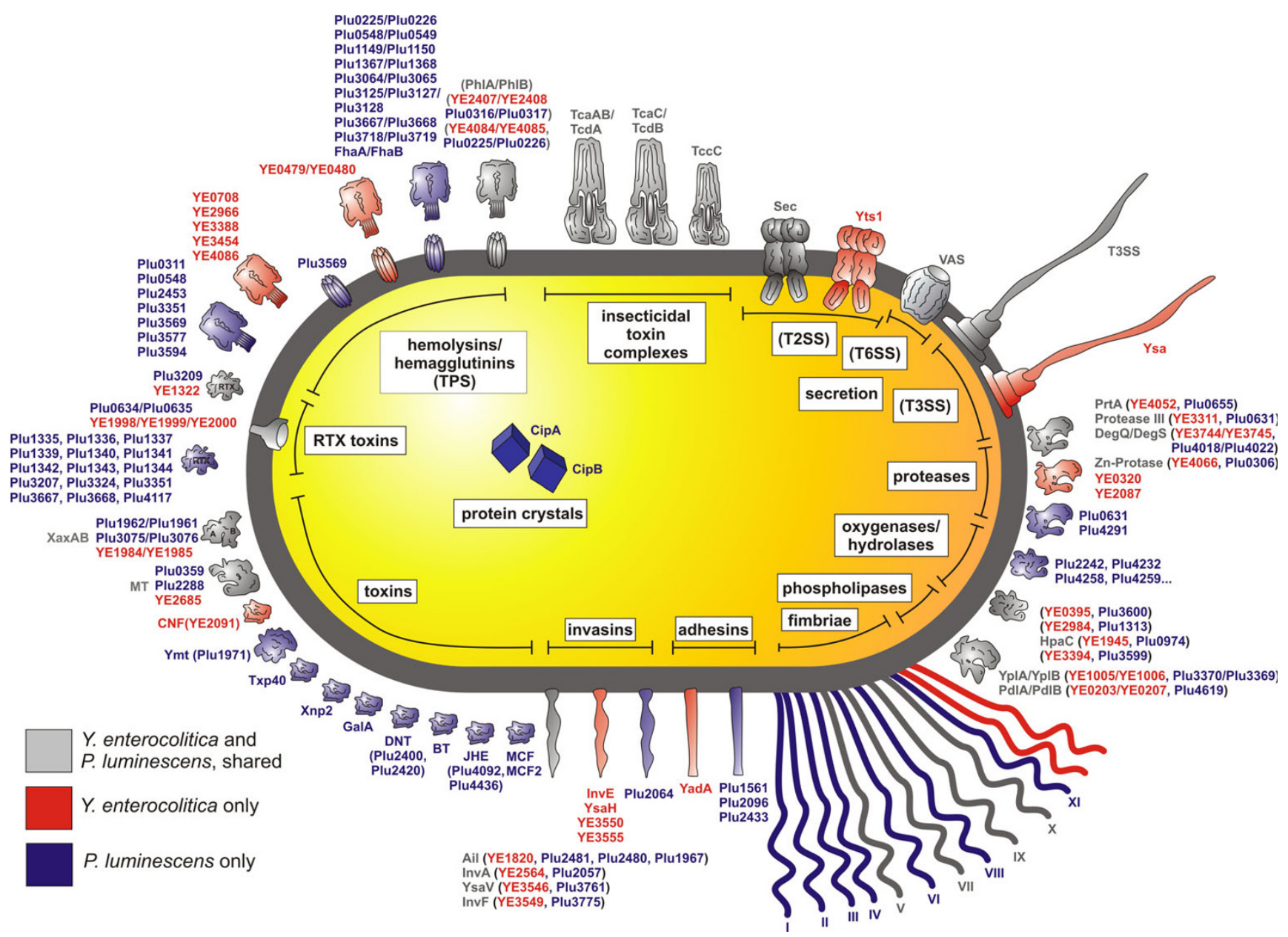

\section{Figure 4}

Virulence factors in $\mathbf{P}$. luminescens and $\mathbf{Y}$. enterocolitica. The different toxins shared by the two organisms are presented in grey colour, toxins only present in P. luminescens or in Y. enterocolitica are depicted in blue or in red, respectively. DNT: Dermonecrotic Toxin, BT: Bacillus thuringiensis like toxin crystal, JHE: Juvenile Hormone Esterase, MCF: "Makes Caterpillars Floppy", MT: Macrophage Toxin, CNF: Cytonecrotic Factor, RTX: "Repeats in toxin", Ymt: Y. pestis murine toxin. The toxins are grouped in functional classes, and the respective homologues in $P$. luminescens and $Y$. enterocolitica are indicated. See text for further details. 
or two tccC genes, are present in the genomes of $Y$. pseudotuberculosis IP32953 and Y. pestis KIM. In P. luminescens, the insecticidal genes are organized in the tcd island harbouring nine $t c d$ - and $t c c$-like genes and several non $t c$-like genes, while further nine tcc-like genes are scattered over the chromosome [24]. The reason for the over-represence of $t c$-like genes in the P. luminescens genome might reflect the different strategies followed by both bacteria within insects, namely the rapid killing for exploiting the victim as a food source in case of $P$. luminescens, and infection of and persistance within the invertebrate host as possibly preferred by $Y$. enterocolitica.

\section{Hemolysins or hemagglutinin-related proteins}

These extracellular toxins target red blood cells to provide access to iron, but often show activity against immune cells, thus contributing to the bacterial response to the immune system of hosts, including phagocytosis by insect blood cells [64]. Hemolysins or surface-associated adhesins, together with their transporters, are sometimes organized as two-partner secretion (TPS) systems, a specialized mechanism for the delivery of large exoproteins [65]. TPS systems have been characterized mainly in pathogenic bacteria, but are also present in other microorganisms. $P$. luminescens and $Y$. enterocolitica TPS systems include the calcium-independent hemolysin PhlA that is transported through the outer membrane and activated by PhlB. Remarkably, their expression is induced by low iron concentration as encountered in the insect host, and phlA/ phlB are up-regulated at $18^{\circ} \mathrm{C}$ compared to $28^{\circ} \mathrm{C}$ in $Y$. ruckeri [66]. Eight other TPS systems are present in P. luminescens, namely Plu0225/Plu0226, Plu0548/Plu0549, Plu1149/Plu1150, Plu1367/Plu1368, Plu3064/Plu3065, Plu3125-3127/3128, Plu3667/Plu3668, and Plu3718/ Plu3719, and further three genes for which the partner locus has not been identified (Fig. 4). In the genome of $Y$. enterocolitica, only three complete TPS systems are present, namely YE0479/YE0480, YE2407/YE2408, (YE4084)YE4085/YE4086, and YE3454 which lacks the activator partner. Except YE0479/YE0480, all have counterparts in the P. luminescens genome. Recently, we have shown that a luciferase reporter insertion into YE0480 is induced at low temperature [67], indicating that this TPS system might contribute to insect pathogenicity and possibly to the host-specificity of $Y$. enterocolitica. The genomes of both pathogens also carry three and five, respectively, further hemolysin/hemagglutinin-related proteins which are absent in the other pathogen (Fig. 4). FhaC which belongs to a family of hemolysin activator proteins related to ShlA from Serratia marcescens is present in both pathogens and also induced at low temperature [67]. The genome sequence of $P$. luminescens exhibits more toxin genes than found in any other bacterial genome sequenced yet, including the genome of $Y$. enterocolitica. Hemolysin-related factors and their transporters discussed above are an example for this redundancy. However, the majority of these $P$. luminescens toxins exhibit highly significant similarities to those of $Y$. enterocolitica, suggesting common progenitors of hemolysins. It is therefore tempting to speculate that hemolytic activities of bacteria had been evolved during the association with insects and then adapted to mammalian hosts. Although it can not be excluded that the hemolysins of Y. enterocolitica act on the immune systems of both the insect and the mammalian host, the genetic overlap of this group of virulence factor between both pathogens, and the low-temperature expression of YE0479/YE0480 and fhaC, indicates the presence of insect-specific hemolysins in the genome of $Y$. enterocolitica.

\section{Repeats-in-toxin (RTX) and other toxins}

RTX proteins constitute another family of toxins that may contribute to the insecticidal activity of the two pathogens. A putative RTX-family toxin transporter is common to both pathogens (YE1998-2000, Plu0634/Plu0635). The $P$. luminescens genome comprises a gene cluster encoding RTX proteins, namely plu1330-1369. Further RTX toxins are encoded by plu3217, plu3324 (both RTX Afamily), plu4117 (own family), and plu3668 (RTX cytotoxin), none of which is present in Y. enterocolitica. This pathogen produces only one RTX protein (YE1322) for which a truncated homologue is found in P. luminescens (Plu3209).

Other examples of toxins common for both bacterial species compared here are homologues of XaxAB, an apoptotic $\mathrm{AB}$ toxin of $X$. nematophila [68], and proteins encoded by the macrophage toxin $(m t)$-like genes Plu2288 and Plu0359 with high similarity to YE2685. cnf encoding the cytonecrosis factor-like toxin is present in $Y$. enterocolitica (YE2091) and P. luminescens ssp. akhurstii strain W14, but not in $P$. luminescens ssp. laumondii strain TT01 (Fig. 4). P. luminescens produces a series of proteins similar to toxins that have been identified in other bacteria, but are absent in Y. enterocolitica. Examples identified are Txp40, a $40 \mathrm{kD}$ insecticidal toxin [69], the nematicidal toxin (Xnp2) first described in $X$. bovienii (accession number AJ296651.1), galA (plu0840) similar to the enterotoxin Ast of Aeromonas hydrophila which is involved in carbohydrate transport and metabolism [70], and two dermonecrotizing toxin-(dnt-) like factors (plu2400 and plu2420). In addition, neither the crystal proteins encoded by cipA and $c i p B$ in $P$. luminescens nor a Bt-like toxin (plu1537) could be found in Y. enterocolitica. A cytonecrosis factor (CNF)-like protein, Pnf, was identified in $P$. luminescens ssp. akhurstii strain W14, but not in P. luminescens ssp. laumondii strain TT01. In P. luminescens, the two paralogs plu4092 and plu4436 encode juvenile hormone esterases (JHE) for which insect toxicity has already been demonstrated [24]. Additionally, neither the locus $m c f$ 
that confers insecticidal activity of $P$. luminescens towards M. sexta [71] by inducing apoptosis [72], nor the homologous gene locus mcf2 (plu3128) [73] are present in the genome of $Y$. enterocolitica. Most of these toxins probably contribute to the higher insect toxicity of $P$. luminescens against the tobacco hornworm in comparison with $Y$. enterocolitica. No homologues of the $Y$. pestis gene coding for enhancin (YPO0339) could be found for which a role in flea colonization was predicted [74].

We also identified several virulence genes and operons that are present in $Y$. enterocolitica, but not in $P$. luminescens, suggesting that they have been acquired by horizontal gene transfer from other bacteria and do not play a role in bacteria-insect association. Examples are SopB, a host cell invasion factor translocated via the type-III secretion system that is present in the emerging human pathogen $P$. asymbiotica, but not in the insect pathogen $P$. luminescens [14], a putative effector protein (YE2447) with proteolytic activity, and a homologue of SrfA which is negatively regulated by PhoP in S. typhimurium [75]. The SrfA homologue has been demonstrated to be up-regulated by environmental temperature [67]. Other virulence factors absent in P. luminescens are the opg cluster (YE1604-1606) and ProP (YE3594), both involved in osmoprotection [76], cellulose biosynthesis (YE4072-4078) associated with protection from chemical and mechanical stress [60], the methionine-salvage pathway (YE3228-3235) also involved in AHL production [23], the putative ADP- ribosyltransferase toxin encoded by $y t x A B$ (ye2124/ ye2123) [77], and the Yersinia heat-stable toxin Yst [78] which is stronger expressed at $28^{\circ} \mathrm{C}$ than at $37^{\circ} \mathrm{C}$ (Table 1).

Summarizing, the large variety of diverse toxins present in $P$. luminescens, but absent in Y. enterocolitica, might contribute to the higher toxicity towards insects of $P$. luminescens in comparison to $Y$. enterocolitica. Toxins only present in Y. enterocolitica are assumed to play a major role in its pathogenicity towards mammalians, and some of them might have been acquired by horizontal gene transfer. Examples of those factors are shown in Fig. 5.

\section{Adhesins and invasins}

Colonization and penetration of epithelial cells, and interaction with immune cells, are key steps during the host infection by pathogens. Many of the pathogen-receptor molecules such as Toll-like receptors or integrins are conserved between invertebrates and mammalians [79]. We therefore investigated if $P$. luminescens and $Y$. enterocolitica that interact with the midgut of diverse hosts use the same adhesion and invasive factors. The most prominent protein of $Y$. enterocolitica involved in attachment to and invasion of mammalian cells is Ail (YE1820) that is homologue to three $P$. luminescens proteins encoded by plu2481, plu2480, and plu1967, and InvA (YE2564) with high similarity to Plu2057. Further invasin genes of $Y$. enterocolitica with counterparts in P. luminescens are $y s a V$

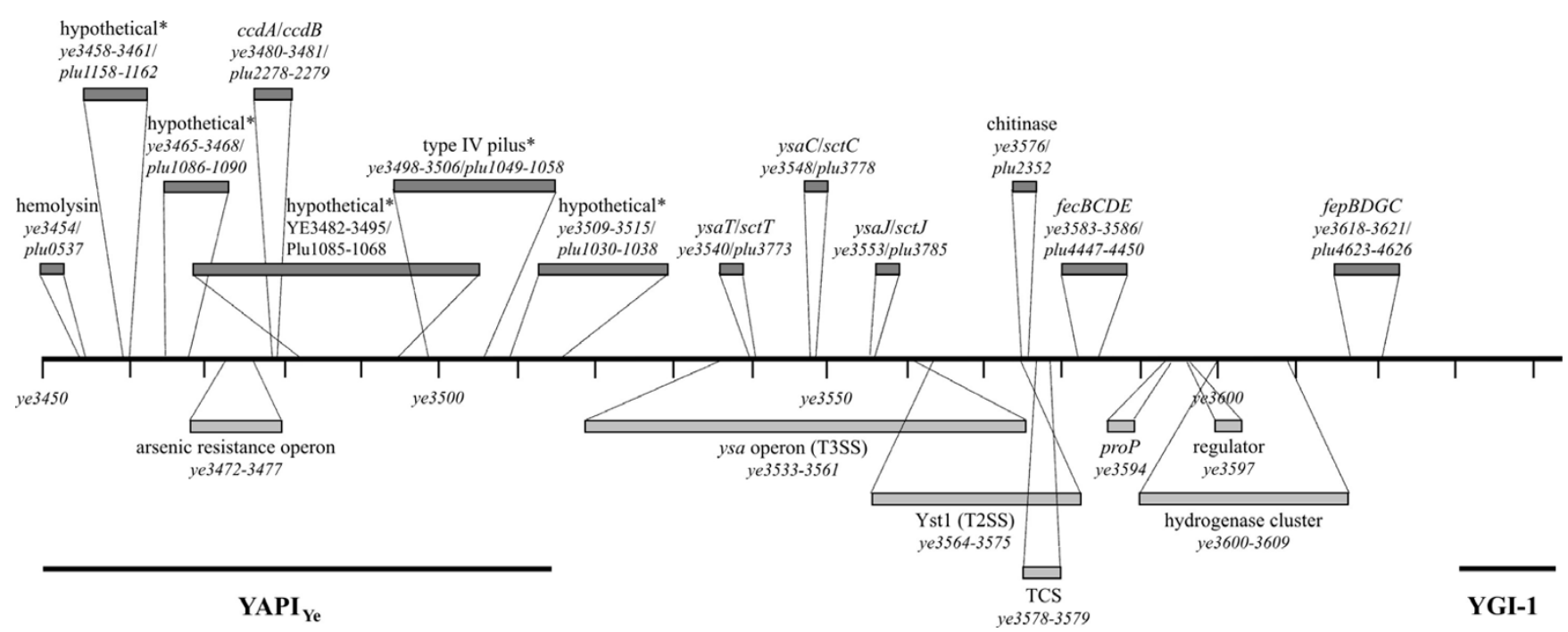

Figure 5

Plasticity zone of $Y$. enterocolitica (YE3450-3644) compared to the $P$. luminescens genome. YAPI ${ }_{Y e}$, a genomic region highly similar to the adhesion pathogenicity island of $Y$. pseudotuberculosis and absent in $Y$. pestis. Sites marked with an asterisk are localized on genome island Plu0958-I I66. In Y. enterocolitica biovars 2-5, a second flagellar gene cluster (Flag-2) is inserted next to ye3610 [120]. Genes, operons or proteins shared by $Y$. enterocolitica and $P$. luminescens are depicted in dark grey colour above the chromosomal scale, and genes without homologue in $P$. luminescens are shown in light grey below the line. See section "Evolution of pathogenicity" for further details. 
(ye3546/plu3761) and invF (ye3549/plu3775). Y. enterocolitica genes not present in $P$. luminescens are ye1873 encoding the adhesin YadA which is maximally expressed at $37^{\circ} \mathrm{C}$, and the invasin genes invE, ysaH, ye3550, and ye3555. The function of the latter two in cell recognition is predicted, but has not yet been demonstrated experimentally. In contrast, $P$. luminescens produces several factors involved in host cell interaction without homologues in Y. enterocolitica, namely Plu2096 which is similar to lectin PA-I, Plu1561 with strong homology to a $\mathrm{Ca}^{2+}$ dependent adhesion molecule, the adhesin Plu2433 similar to a virulence factor of the Gram-negative plant pathogen Erwinia carotovora, EvF, which is involved in colonisation of the $D$. melanogaster gut epithelium [80], and the putative invasin Plu2064. In P. luminescens, eleven fimbrial gene cluster have been identified, four of which (V, VII, IX and X) are also present in $Y$. enterocolitica. Unique for the human pathogen in comparison to P. luminescens are the two fimbrial gene cluster ye2664-2668 and ye2692-2700, both of yet hypothetical function. Thus, invasin and adhesin homologues similar in the two pathogens might contribute to the infection of insect or mammalian hosts, but candidates for insect- and mammalian-specific colonization factors have also been revealed by the genome comparison performed here.

\section{Defensive mechanisms \\ Antimicrobials}

The production of antibiotics is mainly restricted to $P$. luminescens, whereas factors combating antimicrobial host substances play an important role during the infection process of both pathogens compared here. In the genome of $P$. luminescens ssp. laumondii strain TT01, many loci involved in the defense of the insect cadaver against different microbial competitors are present, including nearly 50 genes encoding proteins such as polyketide and peptide synthases putatively involved in antibiotic synthesis and efflux. Interestingly, none of these genes showed significant similarities to sequences of the $Y$. enterocolitica genome. Phage-derived bacteriocins in entomopathogenic bacteria are also presumed to eliminate competing bacteria. More than twenty colicin/pyocin-like factors and putative immunity proteins are unique to $P$. luminescens in comparison to $Y$. enterocolitica. Remarkable exceptions are the toxin/antitoxin system $c c d A / c c d B$, the tolQRAB/pal operon involved in group A colicin translocation, and a colicin production and secretion system (Plu3168/ Plu3869; YE0791/YE1314). Recently, it was reported that PrtS (Plu1382) secreted by P. luminescens, a metalloprotease without counterpart in Y. enterocolitica, specifically induces melanization of the hemolymph, probably to circumvent the innate immune response of the insect [81].

\section{Oxygenases and hydrolases}

$P$. luminescens produces proteins similar to monooxygenases, dioxygenases and hydroxylases that have been suggested to play a role in rapid elimination of insect polyphenols or in the detoxification of reactive oxygen species generated by the invaded host [24]. Examples are the product of plu4258, adjacent to a gene encoding glutathione transferase (plu4259), a putative steroid monooxygenase (Plu4232), and a glycine oxidase (Plu2242), all of which have no counterparts in Y. enterocolitica. Factors present in both pathogens are two monooxigenases encoded by ye1945/hpaC (plu0974) and ye3394/plu3599, and two hydroxylases encoded by ubiH (ye3395/plu3600) and ubiF (ye2984/plu1313). It is therefore possible that the $Y$. enterocolitica homologues of these enzymes are involved in persistence within the insect, a mechanism which is also used by $P$. luminescens.

\section{Secretion and exoenzymes}

In Y. enterocolitica, two type-III secretion systems (T3SS) essential for virulence in the mammalian host are encoded on pYV and by the $y s a$ operon (YE3533-3561) $[23,82]$. The P. luminescens genome encodes one T3SS which is highly similar to the plasmid-encoded T3SS of $Y$. enterocolitica and probably involved in the secretion of virulence proteins or in immunomodulation of the insect response to an infection. Interestingly, the T3SS of $Y$. pestis has recently been demonstrated to translocate insecticidal toxins, providing evidence that they support the transmission of the plague agent by insects [83]. Furthermore, the flagellar export apparatus of $Y$. pseudotuberculosis functions as a secretion system for the virulence-associated phospholipase YplA [84]. The typical effector proteins of $Y$. enterocolitica are also present in P. luminescens. The P. luminescens Lop effector proteins are homologs of the Yop effector proteins of Y. enterocolitica [85]. The LopT effector protein of $P$. luminescens can be injected by $Y$. enterocolitica into mammal cells [86], underlining the idea that both T3SS act similarly. Furthermore, we found homologues of the $Y$. enterocolitica low-calcium-response genes $(\mathrm{lcrH}$, $l c r V$, and $l r c D$ ) in P. luminescens (plu3757, plu3758, sctV) which further supports this hypothesis. The fact that $Y$. enterocolitica a second T3SS (Ysa) is not shared by P. luminescens confirms its solely role in human pathogenicity [87].

Both P. luminesens and Y. enterocolitica share a Sec protein translocation system that belongs to the type-II secretion systems (T2SS). These are substrate-specific secretion machineries that share a similar architecture and secretion mechanism [88]. Proteins secreted by these systems are mainly virulence determinants such as exotoxins like the Cholera toxin of Vibrio cholerae, pili, and S-layer components (see [89] for review). Additionally to the Sec-system, $Y$. enterocolitica produces a T2SS named Yts1, which has 
been found to be important for virulence in mice [90]. Because there is no counterpart of Yts 1 present in P. luminescens, one can speculate that the major parts of type-II dependent secreted proteins which are important for insect association of $Y$. enterocolitica are translocated via the Sec system.

Recently, a novel protein secretion mechanism translocating proteins without an $\mathrm{N}$-terminal leader sequence has been described, termed type-VI secretion system, T6SS (see [91] for review). The genes encoding these kinds of secretion systems were named vas (virulence associated secretion), and homologues are widespread in Gram-negative bacteria. VAS-dependent secretion has been found to be important for virulence of Vibrio cholerae [92] as well as for Pseudomonas aeruginosa [93], and T6SS are assumed to play a major role in virulence in many Gram-negative bacteria [91]. P. luminescens as well as Y. enterocolitica harbour homologues of the vas genes, indicating that several proteins involved in virulence are secreted via this pathway.

Both pathogens secrete lipases and proteases that are assumed to contribute to immunosuppression, degradation of insect tissues or antibacterial peptides, and host bioconversion (Fig. 4). One of those exoenzymes is the phospholipase A (YplA) with an accessory protein (YplB) of $Y$. enterocolitica (YE1005/YE1006) which are also present in P. luminescens (Plu3370/Plu3369). YplA contributes to pathogenesis of $Y$. enterocolitica in a mouse model [94], suggesting a role in virulence against insects for the P. luminescens homologue. Remarkably, yplA is induced at low temperature (Table 1), and its expression is known to be regulated by the master regulator FlhDC [94], indicating that YplA plays a role in pathogenicity both against human and insect hosts. Two additional phospholipases are present in $Y$. enterocolitica, namely PdlA (YE0203) and PdlB (YE0207), the latter one a homologue of Plu4619. This overlap is another example for $Y$. enterocolitica enzymes probably involved rather in the association with invertebrates than in pathogenicity towards mammalians. Plu1971 of $P$. luminescens is a protein which contains two phospholipase D motifs. Furthermore, it shares homologies to the plasmid (pMT1)encoded murine toxin (Ymt) of $Y$. pestis. It was suggested that $y m t$ has been acquired by $Y$. pestis from $P$. luminescens or a close relative [24]. Ymt is essential for flea colonization by $Y$. pestis and is regulated by AHL both in Y. pestis [95] and P. luminescens (R. Heermann, unpublished data), indicating that $\mathrm{Ymt}$ is also required for insect colonization by $P$. luminescens. Due to its absence in $Y$. enterocolitica, Ymt is another example for the high diversity of genetic determinants that are used by closely related bacterial pathogens to interact with their insect hosts.
There are several other exoenzymes present either in $Y$. enterocolitica or in P. luminescens, which do not have a homologue counterpart in the other bacterium. Examples are the ten triacylglycerol lipases of $P$. luminescens or the three identified lipases of $Y$. enterocolitica. However, homologies are observed for six secreted proteases of both organisms. Among them is PrtA (Plu0655/YE4052), a zinc metalloprotease that is involved in the immunosuppressive activity of X. nematophila [96], and that has also been shown to be involved in insect gut colonization of $P$. luminescens [97]. Further examples for shared proteases are another Zn-dependent protease (Plu0306/YE4066), the protease III (Plu0631/YE3311), and DegQ/DegS (YE3744/YE3745/Plu4018/Plu4022). The high number of homologs in both organisms suggests an important and similar role of these exoproteases in the infection process. We also identified two proteases in each pathogen (Plu4291, Plu0631, YE0320, and YE2087) without a homologue in the other bacterium. We speculate that these $Y$. enterocolitica proteases could be involved in the infection process in mammals, whereas the P. luminescens proteases are rather used for nutrient bioconversion than for the infection process.

\section{Metabolism}

While many specific virulence factors, which enable the microbes to overcome the various physical and biochemical barriers of the infected hosts, have been investigated in detail, little attention has been given to the metabolic requirements and substrate availability of bacteria in vivo. Both in insects and mammals, pathogens get access to host-specific nutrients, but also encounter substrate limitations such as low iron concentration. In this chapter, we focus on metabolic pathways of P. luminescens and Y. enterocolitica absent in E. coli, induced at low temperature, or already known to be virulence-associated.

\section{Degradative pathways}

$P$. luminescens and Y. enterocolitica share loci encoding several common degradation pathways that are absent in $E$. coli $\mathrm{K}-12$, including the urease operon (ureABCEFGD), the genes involved in myo-inositol degradation, and the histidine degradation operon (hutHUCGI). These pathways might help the bacteria to gain access to sufficient amounts of substrates and thus to proliferate in the hemolymph of the insect larvae. We recently reported that the genes of the urease operon as well as a histidine ammonia lyase (ye3021/plu1240), which deaminates histidine to urocanic acid, are highly induced in $Y$. enterocolitica upon temperature decrease [67]. Beside arginine $(5.17 \mu \mathrm{mol} / \mathrm{g})$, lysine $(12.23 \mu \mathrm{mol} / \mathrm{g})$, serine $(6.77 \mu \mathrm{mol} / \mathrm{g})$ and proline $(6.40 \mu \mathrm{mol} / \mathrm{g})$, histidine $(5.04 \mu \mathrm{mol} / \mathrm{g})$ is the most abundant free amino acids in the Hyalophora gloveri fat body [98]. 
The synthesis of vitamin B12 that occurs only anaerobically is required for the degradation of 1,2-propanediol by the products of the $p d u$ operon, as well as of ethanolamine by the eutABC-encoded enzymes. The cobalaminedependent anaerobic growth of Salmonella typhimurium on both these substrates has been shown to be supported by the alternative electron acceptor tetrathionate whose respiration is facilitated by the tetrathionate reductase gene cluster $\operatorname{ttr}[99,100]$. Beside $S$. typhimurium, all these genetic determinants were found only in few other bacteria, namely the human pathogens Listeria monocytogenes, and Clostridium perfringens [101]. Y. enterocolitica carries the genes encoding tetrathionate reductase $(\operatorname{tr} A B C)$ and the TCS TtrRS (YE1613-1617). The gene clusters for cobalamin synthesis and propanediol degradation are located on a 40-kb genomic island (ye2707-2750), but the eutABC operon is missing. Propanediol degradation by $Y$. enterocolitica might also be supported by YE4187 with a putative GlcG domain which is predicted to be involved in glycolate and propanediol utilization. The cobalamine synthesis genes and the eut $A B C$ operon, but not $t t r C, t t r R$, $t t r S$ and the propanediol utilization gene cluster, are also present in the genome of $P$. luminescens, suggesting the degradation of phosphatidylethanolamine as additional energy source in the insect host [102].

Further metabolic genes common to both pathogens are $d c t A$ responsible for transport of C4- dicarboxylates across the membrane, the UhpABC regulatory system controlling the hexose phosphate transport by UhpT, and the three $\mathrm{Mg}^{2+}$ transport systems CorA, MgtA and MgtB. The $u h p A B C$ operon as well as $m g t C$ encoding the $\mathrm{Mg}^{2+}$ transport ATPase subunit have been found to be induced at low temperature in Y. enterocolitica [67], indicating a relevance for these metabolic genes for P. luminescens and Y. enterocolitica during insect infection. Another gene, gltP encoding a glutamate-aspartate symporter, is also up-regulated at low temperature in $Y$. enterocolitica, but lacks a counterpart in $P$. luminescens. Furthermore, both insecticidal bacteria produce a chitin-binding-like protein (Plu2352, YE3576), but chitinase-like proteins (Plu2235, Plu2458 and Plu2461) are without homologues in Y. enterocolitica. This fact correlates once more with the separate lifestyle of both bacteria, e.g. association with the host and persistence for $Y$. enterocolitica, and association and bioconversion of the insect in case of $P$. luminescens.

\section{Iron uptake}

Bacteria use two different strategies to acquire sufficient amounts of iron, namely the expression and secretion of high-affinity iron-binding compounds called siderophores, and the production of receptors for iron carriers such as heme. Genes involved in the biosynthesis, transport and regulation of the siderophore yersiniabactin are clustered in the high pathogenicity island of Y. entero- colitica [103] and have counterparts in P. luminescens (plu2316-2324). Remarkably, yersiniabactin is absent in all Y. enterocolitica strains beside biovar 1B. Present in both bacterial organisms compared here are also genes encoding a hemine uptake system (ye0323-0332/plu26312636), the YfeABCD transporter system of chelated iron, the ferrous $\left(\mathrm{Fe}^{2+}\right)$ iron transporter proteins $\mathrm{FeoAB}$, the AfuABC/SfuABC ferric $\left(\mathrm{Fe}^{3+}\right)$ transporter, the enterobactin and its transporter (FepBDCG), the FecABCDE ABC transporter system, and several putative hemin/siderophore/ iron uptake proteins (YE1459-1461/Plu2850-2852), YE3190/Plu2853, and YE0555/Plu3738). The proteins encoded by the $P$. luminescens fecIRABCDE operon are similar to the components of the E. coli $\mathrm{Fe}^{3+}$-dicitrate transport system. Homologues are present in the genome of $Y$. enterocolitica, but scattered over the chromosome. In addition, $Y$. enterocolitica produces two heme-protein acquisition sytems (YE0123-126, YE2180-2182), a second SfuABC system, the ferrichrome binding and transport proteins (YE0730-0732), a putative siderophore (YE0704), and a hemin storage system (YE2481-2484). None of these iron acquisition systems is present in $P$. luminescens which in contrast produces the siderophore photobactin [104]. Furthermore, P. luminescens encodes two putative heme-binding hemopexin-like proteins, the photopexins PpxA (Plu4242) and PpxB (Plu4243), which are the first hemopexins found in bacteria. It is suggested that the photopexins may be used by P. luminescens to scavenge iron containing compounds from insects [105]. Interestingly, three gene loci involved in iron acquisition, namely the genes encoding the hemin storage system, the yersiniabactin and the enterobactin transporter FepG, have been demonstrated to be up-regulated upon temperature decrease in $Y$. pestis or $Y$. ruckeri, respectively (Table $1)$.

This large set of iron, hemin, heme and siderophore transporters underlines the importance of iron availability for the life cycles of $P$. luminescens and $Y$. enterocolitica. It also indicates that iron acquisition is a prerequisite for the infection process of pathogenic bacteria not only in mammalian, but also in invertebrate hosts, and underlines the suggestion that genetic determinants of invertebrate pathogens such as $P$. luminescens include the progenitors of virulence factors against vertebrates $[79,106]$.

\section{Tricarboxylate utilization}

The TctE/TctD system is the only TCS of $P$. luminescens without homologue in Y. enterocolitica (see section "Twocomponent signal transduction", Fig. 2). It controls the expression of the tctCBA operon encoding the tricarboxylic acid transport system TctCBA [107]. The transporter is supposed to facilitate uptake of citrate, fluorocitrate, isocitrate and cis-acconitate for aerobic utilization $[108,109]$. The $\mathrm{Na}^{+}$dependent citrate symporter CitS of S. enterica, 
which the Y. enterocolitica protein YE2507 is homologous to, is induced by the CitA/CitB system for fermentation of citrate under anoxic conditions [110], indicating a general difference of citrate utilization in $P$. luminescens and $Y$. enterocolitica. While $Y$. enterocolitica explores citrate for anaerobic metabolism, it is most likely that the specific uptake of citrate and other tricarboxylic acids by TctCBA is used by $P$. luminescens upon entering the insect host where enough citrate is available. The specific up-regulation of the tricarboxylic acid cycle (TCA) enzymes within a host has also been described for other microorganisms. For example, sucA encoding a subunit of $\alpha$-ketoglutarate synthase and acnA encoding the aconitase have been found to be induced in $V$. cholerae during host infection [111,112], and a complete TCA cycle is also required for S. typhimurium virulence [113]. We also observed induction of sucA in P. luminescens in the insect host Galleria mellonella (R. Heermann, unpublished data). This finding underlines the hypothesis that the citric cycle enzymes used under aerobic conditions are up-regulated as a specific adaptation of the metabolic activity in the nutrient rich insect host. To guarantee an optimal amount of tricarboxylic acids within the cell, TctE might specifically sense the presence of tricarboxylic acids and/or signals of the host. $Y$. enterocolitica and $Y$. pestis, in contrast exhibit upregulation of all TCA genes upon temperature shift from $26^{\circ} \mathrm{C}$ to $37^{\circ} \mathrm{C}[114,115]$. Therefore, it is obvious that $Y$. enterocolitica and $P$. luminescens use different sensing and utilization strategies for tricarboxylates.

\section{Temperature-dependent genes}

Temperature is a key environmental signal to enable bacterial adaptation to diverse hosts. In Yersinia, temperaturedependent gene expression has been described to be an important theme in bacterial mechanisms of pathogenesis towards humans [116]. However, the biological role of genes repressed at body temperature, but induced at environmental temperature, has been underinvestigated so far. By data mining, we identified 32 genes or gene loci of Yersinia spp. that exhibit stronger expression with temperature decrease (Table 1). 19 of them have a homologue in $P$. luminescens. Most genes belong to the groups of offensive virulence factors, regulators, and metabolic enzymes. The data have derived from expression profiling in vitro and cannot directly be translated to the in vivo situation. Moreover, several genes induced at lower temperature such as inv, yst or $y$ plA affect the virulence properties of $Y$. enterocolitica in mice [87]. However, low temperaturedependent expression of the genes in Table 1 suggests that they also play a role during the insect stage of $Y$. enterocolitica, or that they have evolved from bacteria-insect interaction and then adapted to pathogenicity towards mammals. Some of these low temperature-induced genes are restricted to a narrow spectrum of bacterial genera such as Burkholderia, Pseudomonas, Serratia, or Erwinia, all of which are known to be associated with soil, plants or insects. Other genes of Table 1 are present in a broader range of bacteria, and their expression might depend on regulatory mechanisms different from that of $Y$. enterocolitica. This pathogen is non-motile at body temperature, and a connection between motility and virulence is welldocumented $[116,117]$. For example, a non-motile flhDC mutant of $Y$. enterocolitica secretes larger amounts of Yop proteins encoded by the pYV plasmid than the wild-type bacteria [118]. Recently, it was shown that the flagellar master-operon of $X$. nematophila regulates the expression of a novel hemolysin which is required for full virulence of $X$. nematophila against insects [119]. We therefore speculate that motility essentially contributes to the control of the $Y$. enterocolitica switch between two pathogenicity phases towards mammalians and invertebrates [120]. In evolutionary terms, environmental temperature, but not $37^{\circ} \mathrm{C}$, appears as the ancient signal for the expression of many genes involved in pathogenicity, confirming the idea that the biological function of many virulence factors has been evolved during the association of bacteria with poikilothermic organisms (see below).

\section{Evolution of pathogenicity}

It has been suggested that bacteria-invertebrate interactions do not only play a role in the transmission of human pathogens but have also shaped their evolution [79]. We identified several common loci representing ancestral clusters of genes important in Y. enterocolitica and P. luminescens pathogenesis that might have evolved during the association of bacteria with invertebrates, the so-called "pre-vertebrate" pathosphere [121] and then been adapted to more recent pathologies in mammalians. Examples are yersiniabactin, quorum sensing-like regulators, or the urease operon. The complexity of this evolutionary concept is also demonstrated by the fact that the immune systems both of invertebrates and vertebrates are based on phagocytic cells that are attacked by hemolysins, T3SS effector proteins, and many other toxins described above. Thus, it can not be excluded that these virulence factors are able to act on both immune systems [121]. The fact that $P$. asymbiotica has been found to be pathogenic against humans [14] strengthens this hypothesis. Thus, $P$. asymbiotica might be an evolutionary link that is evolving from an insect to a mammal-pathogen. Another example that might enlighten the evolution of bacterial pathogenicity is the plasticity zone (PZ) of Y. enterocolitica, a 199 $\mathrm{kb}$ key locus for high pathogenicity that includes $\mathrm{YAPI}_{\mathrm{Ye}^{\prime}}$ secretion systems, hydrogenase loci essential for gut colonization of S. typhimurium and H. pylori [122], and iron acquisition systems. A second flagellar cluster, Flag-2, is also located within the PZ of $Y$. enterocolitica biotypes 2-5 [120]. It is assumed that the PZ has not been acquired by a single event of gene transfer, but through a series of independent insertions [23]. A comparison of the PZ 
sequence with the genome of $P$. luminescens is depicted in Fig. 5. A region highly similar to $\mathrm{YAPI}_{\mathrm{Ye}}$ is the genome island plu0958-1166 carrying a hemolysin, hypothetical genes, the toxin/antitoxin system $\mathrm{CcdA} / \mathrm{CcdB}$, and the type IV pilus. Only few other genes or operons of the PZ are also present in $P$. luminescens, namely a chitinase, two iron acquisition systems, and three $y$ s $a$ genes, thus confirming the idea of a patchwork of horizontally acquired genes within the PZ [23]. However, given the extensive transfer of virulence factors between bacteria, the history of pathogen evolution still requires further investigation.

\section{Conclusion}

The comparison of $Y$. enterocolitica and P. luminescens at the genomic level performed here provides the database for a better understanding of the genetic basis for their distinct behaviour towards invertebrates and mammals. $Y$. enterocolitica is expected to switch between two pathogenicity phases against insects and mammalians, while the genome of $P$. luminescens must contain the modulators and regulators necessary to change the bacterium from a state of symbiosis with nematodes to pathogenicity against insects, and also from symbiosis-proficient primary variants to symbiosis-deficient secondary variants [17]. Those adaptational processes must be precisely regulated by the bacteria. It was assumed that there are parallels in the regulation of pathogenicity in mammals and insect pathogens $[41,123]$. However, molecular components of the regulatory networks controlling pathogenicity and mutualism have recently been demonstrated to be very different between $P$. luminescens and $X$. nematophilus with similar life cycles [124]. Dissecting the genomes of $Y$. enterocolitica and $P$. luminescens for putative key regulators, we identified factor groups (AI-2, PAS-4/LuxR like receptors) possibly involved in pathogen-insect association only, those with members contributing to either insect or mammalian pathogenicity (QS, TKS, Usp), and c-di-GMP signalling probably not involved in regulation of activities against insects. Certainly, the question whether fundamental differences in regulatory networks reflect how each of these two bacteria specifically interacts with either the insect or the human host remains to be addressed in more detail.

Bioconversion of its insect hosts is an important stage in the lifecycle of $P$. luminescens. This fact might explain the high number of antibacterial factors directed against possible competitors that are going to colonize the same insect cadaver or that are already present in the insect gut flora [17]. However, no corresponding determinants were identified in the genome of $Y$. enterocolitica. Moreover, $P$. luminescens is pathogenic to a variety of insect larvae, and a dose of $<5$ colony-forming units directly injected into the blood system is sufficient to kill within 48-72 $\mathrm{h}$ [124]. In contrast, only highly concentrated protein extracts of $Y$. enterocolitica are toxic for M. sexta [7], and a low insect larvae mortality has been observed following injection of approximately $3.5 \times 10^{6} \mathrm{Y}$. enterocolitica cells into the hemolymph (T. M. Fuchs, unpublished data). This data strongly suggests that $Y$. enterocolitica, similar to $Y$. pestis, has developed a strategy to infect and proliferate in insects, and use these organisms rather as transmission vectors than as pure nutrient source.

Summarizing, Y. enterocolitica and P. luminescens have evolved partially different and partially similar and therefore probably conserved mechanisms to detect and to react on the insect host. Up to the present time, we are far away from understanding the complexity of bacteriainvertebrate interactions. With the genome comparison carried out here, however, we uncovered several genes which are promising candidate genes involved in insect association and pathogenicity, and therefore created a promising basis for future experimental work.

\section{Methods}

Accession numbers of the genome of $Y$. enterocolitica strain 8081v are AM286415 and AM286416 (plasmid), of the insecticidal toxin genes AJ920332, and of the genome of P. luminescens subsp. laumondii strain TT01 BX470251. For gene annotation, functional assignments and BLAST analysis, we used the server of the Sanger Institute and the Pasteur Institute. Genome comparison was performed using the ACT software [125], and the GECO comparative genome analysis software [126]. For protein domain analysis, we used the CDART [127], SMART [128] and Pfam [129] algorithms on the NCBI web server. Proteins containing special protein domains were identified by performing a BLAST search of the domain sequence on the genomes of the respective organisms. The threshold for the consideration of protein homologies was a significance value of $<10^{-04}$ and an identity on the amino acid level of $>22 \%$ in the BLAST analysis.

\section{Abbreviations}

TCS: two-component system; TPS: two partner secretion; T2SS: type-II secretion system; T3SS: type-III secretion system; T6SS: type-VI secretion system

\section{Authors' contributions}

$\mathrm{RH}$ and TMF designed and coordinated the project, carried out the genome analysis, and drafted the manuscript. Both authors have read and approved the final manuscript.

\section{Acknowledgements}

The authors thank Torsten Hain for support with the GECO analysis tool, and Siegfried Scherer, Heinrich Jung, and Roy Gross for critical reading of the manuscript. We apologize to those whose research articles are not cited here. 


\section{References}

I. Fukushima H, Ito Y, Saito K, Tsubokura M, Otsuki K: Role of the fly in the transport of Yersinia enterocolitica. Appl Environ Microbiol 1979, 38:1009-1010.

2. Pianetti A, Bruscolini F, Baffone W, Brandi G, Salvaggio L, Biffi MR Albano A: Yersinia enterocolitica and related species isolated in the Pesaro and Urbino area (Italy) from I98I to I986. J Appl Bacteriol 1990, 68:133-137.

3. Rahuma N, Ghenghesh KS, Ben Aissa R, Elamaari A: Carriage by the housefly (Musca domestica) of multiple-antibiotic-resistant bacteria that are potentially pathogenic to humans, in hospital and other urban environments in Misurata, Libya. Ann Trop Med Parasitol 2005, 99:795-802.

4. Zurek L, Denning SS, Schal C, Watson DW: Vector competence of Musca domestica (Diptera: Muscidae) for Yersinia pseudotuberculosis. J Med Entomol 200I, 38:333-335

5. Deng W, Burland V, Plunkett G 3rd, Boutin A, Mayhew GF, Liss P Perna NT, Rose DJ, Mau B, Zhou S, Schwartz DC, Fetherston JD, Lindler LE, Brubaker RR, Plano GV, Straley SC, McDonough KA, Nilles ML, Matson JS, Blattner FR, Perry RD: Genome sequence of Yersinia pestis KIM. J Bacteriol 2002, I 84:460 I-46II.

6. Chain PS, Carniel E, Larimer FW, Lamerdin J, Stoutland PO, Regala WM, Georgescu AM, Vergez LM, Land ML, Motin VL, Brubaker RR, Fowler J, Hinnebusch J, Marceau M, Medigue C, Simonet M, ChenalFrancisque V, Souza B, Dacheux D, Elliott JM, Derbise A, Hauser LJ, Garcia E: Insights into the evolution of Yersinia pestis through whole-genome comparison with Yersinia pseudotuberculosis. Proc Natl Acad Sci USA 2004, I 0 I: I 3826- I383 I.

7. Bresolin G, Morgan JA, Ilgen D, Scherer S, Fuchs TM: Low temperature-induced insecticidal activity of Yersinia enterocolitica. Mol Microbiol 2006, 59:503-512.

8. Erickson DL, Waterfield NR, Vadyvaloo V, Long D, Fischer ER, ffrench-Constant R, Hinnebusch BJ: Acute oral toxicity of Yersinia pseudotuberculosis to fleas: implications for the evolution of vector-borne transmission of plague. Cell Microbiol 2007, 9:2658-2666.

9. Achtman M, Zurth K, Morelli G, Torrea G, Guiyoule A, Carniel E: Yersinia pestis, the cause of plague, is a recently emerged clone of Yersinia pseudotuberculosis. Proc Natl Acad Sci USA 1999, 96: | 4043-| 4048.

10. Pinheiro VB, Ellar DJ: Expression and insecticidal activity of Yersinia pseudotuberculosis and Photorhabdus luminescens toxin complex proteins. Cell Microbiol 2007, 9:2372-2380.

II. Forst S, Dowds B, Boemare N, Stackebrandt E: Xenorhabdus and Photorhabdus spp.: bugs that kill bugs. Annu Rev Microbiol 1997, 5 I:47-72.

12. Poinar GO: Description and biology of a new insect parasitic rhabditoid Heterorhabditis bacteriophora. Nematologica 1975, 21:463-470.

13. Weissfeld AS, Halliday RJ, Simmons DE, Trevino EA, Vance PH, O'Hara CM, Sowers EG, Kern R, Koy RD, Hodde K, Bing M, Lo C, Gerrard J, Vohra R, Harper J: Photorhabdus asymbiotica, a pathogen emerging on two continents that proves that there is no substitute for a well-trained clinical microbiologist. J Clin Microbiol 2005, 43:4I52-4I55.

14. Tounsi S, Blight M, Jaoua S, de Lima Pimenta A: From insects to human hosts: Identification of major genomic differences between entomopathogenic strains of Photorhabdus and the emerging human pathogen Photorhabdus asymbiotica. Int J Med Microbiol 2006, 296:521-530.

15. Peel MM, Alfredson DA, Gerrard JG, Davis JM, Robson JM, McDougall RJ, Scullie BL, Akhurst RJ: Isolation, identification, and molecular characterization of strains of Photorhabdus luminescens from infected humans in Australia. J Clin Microbiol 1999, 37:3647-3653.

16. Han R, Ehlers RU: Pathogenicity, development, and reproduction of Heterorhabditis bacteriophora and Steinernema carpocapsae under axenic in vivo conditions. J Invertebr Pathol 2000, 75:55-58.

17. ffrench-Constant R, Waterfield N, Daborn P, Joyce S, Bennett $H, A u$ C, Dowling A, Boundy S, Reynolds S, Clarke D: Photorhabdus: towards a functional genomic analysis of a symbiont and pathogen. FEMS Microbiol Rev 2003, 26:433-456.

18. Joyce SA, Watson RJ, Clarke DJ: The regulation of pathogenicity and mutualism in Photorhabdus. Curr Opin Microbiol 2006, 9:127-132.
19. Smigielski AJ, Akhurst RJ, Boemare NE: Phase Variation in Xenorhabdus nematophilus and Photorhabdus luminescens: Differences in Respiratory Activity and Membrane Energization. Appl Environ Microbiol 1994, 60: I 20- I 25.

20. Turlin E, Pascal G, Rousselle JC, Lenormand P, Ngo S, Danchin A, Derzelle S: Proteome analysis of the phenotypic variation process in Photorhabdus luminescens. Proteomics 2006, 6:2705-2725

2I. Forst S, Nealson K: Molecular biology of the symbiotic-pathogenic bacteria Xenorhabdus spp. and Photorhabdus spp. Microbiol Rev 1996, 60:21-43.

22. Williamson VM, Kaya HK: Sequence of a symbiont. Nat Biotechnol 2003, 2 I: I 294-I 295.

23. Thomson NR, Howard S, Wren BW, Holden MT, Crossman L, Challis GL, Churcher C, Mungall K, Brooks K, Chillingworth T, Feltwell T, Abdellah Z, Hauser H, Jagels K, Maddison M, Moule S, Sanders M, Whitehead S, Quail MA, Dougan G, Parkhill J, Prentice MB: The Complete Genome Sequence and Comparative Genome Analysis of the High Pathogenicity Yersinia enterocolitica Strain 808I. PLoS Genet 2006, 2:e206.

24. Duchaud E, Rusniok C, Frangeul L, Buchrieser C, Givaudan A, Taourit S, Bocs S, Boursaux-Eude C, Chandler M, Charles JF, Dassa E, Derose R, Derzelle S, Freyssinet G, Gaudriault S, Medigue C, Lanois A, Powell $K$, Siguier P, Vincent R, Wingate V, Zouine $M$, Glaser P, Boemare N, Danchin A, Kunst F: The genome sequence of the entomopathogenic bacterium Photorhabdus luminescens. Nat Biotechnol 2003, 2 I: I307-1313.

25. Stock AM, Robinson VL, Goudreau PN: Two-component signal transduction. Annu Rev Biochem 2000, 69:183-2। 5.

26. Parkinson JS, Kofoid EC: Communication modules in bacterial signaling proteins. Annu Rev Genet 1992, 26:7I-II 2.

27. Goudreau PN, Stock AM: Signal transduction in bacteria: molecular mechanisms of stimulus-response coupling. Curr Opin Microbiol 1998, I:160-169.

28. Derzelle S, Ngo S, Turlin E, Duchaud E, Namane A, Kunst F, Danchin A, Bertin P, Charles JF: AstR-AstS, a new two-component signal transduction system, mediates swarming, adaptation to stationary phase and phenotypic variation in Photorhabdus luminescens. Microbiology 2004, I 50:897-910.

29. Grabenstein JP, Marceau M, Pujol C, Simonet M, Bliska JB: The response regulator PhoP of Yersinia pseudotuberculosis is important for replication in macrophages and for virulence. Infect Immun 2004, 72:4973-4984.

30. Flamez C, Ricard I, Arafah S, Simonet M, Marceau M: Phenotypic analysis of Yersinia pseudotuberculosis 32777 response regulator mutants: New insights into two-component system regulon plasticity in bacteria. Int J Med Microbiol 2007.

31. Bennett HP, Clarke DJ: The pbgPE operon in Photorhabdus luminescens is required for pathogenicity and symbiosis. J Bacteriol 2005, 187:77-84.

32. Oyston PC, Dorrell N, Williams K, Li SR, Green M, Titball RW, Wren $B W:$ The response regulator $P$ ho $P$ is important for survival under conditions of macrophage-induced stress and virulence in Yersinia pestis. Infect Immun 2000, 68:34I 9-3425.

33. Waters CM, Bassler BL: Quorum sensing: cell-to-cell communication in bacteria. Annu Rev Cell Dev Biol 2005, 21:319-346.

34. Atkinson S, Chang CY, Sockett RE, Camara M, Williams P: Quorum sensing in Yersinia enterocolitica controls swimming and swarming motility. I Bacteriol 2006, I 88: |45|-|46|

35. Michael B, Smith JN, Swift S, Heffron F, Ahmer BM: SdiA of Salmonella enterica is a LuxR homolog that detects mixed microbial communities. J Bacteriol 200I, I 83:5733-5742.

36. Smith JN, Ahmer BM: Detection of other microbial species by Salmonella: expression of the SdiA regulon. I Bacteriol 2003, I 85:1357-1366.

37. Van Houdt R, Aertsen A, Moons P, Vanoirbeek K, Michiels CW: Nacyl-L-homoserine lactone signal interception by Escherichia coli. FEMS Microbiol Lett 2006, 256:83-89.

38. Toh H, Weiss BL, Perkin SA, Yamashita A, Oshima K, Hattori M, Aksoy S: Massive genome erosion and functional adaptations provide insights into the symbiotic lifestyle of Sodalis glossinidius in the tsetse host. Genome Res 2006, I 6: I 49-I56.

39. Schauder S, Shokat K, Surette MG, Bassler BL: The LuxS family of bacterial autoinducers: biosynthesis of a novel quorum-sensing signal molecule. Mol Microbiol 200 I, 4I:463-476. 
40. Surette MG, Miller MB, Bassler BL: Quorum sensing in Escherichia coli, Salmonella typhimurium, and Vibrio harveyi: a new family of genes responsible for autoinducer production. Proc Natl Acad Sci USA 1999, 96:1639-1644.

41. Derzelle S, Duchaud E, Kunst F, Danchin A, Bertin P: Identification, characterization, and regulation of a cluster of genes involved in carbapenem biosynthesis in Photorhabdus luminescens. Appl Environ Microbiol 2002, 68:3780-3789.

42. Krin E, Chakroun N, Turlin E, Givaudan A, Gaboriau F, Bonne I, Rousselle JC, Frangeul L, Lacroix C, Hullo MF, Marisa L, Danchin A Derzelle S: Pleiotropic role of quorum-sensing autoinducer 2 in Photorhabdus luminescens. Appl Environ Microbiol 2006 72:6439-645I.

43. Dubrovsky EB: Hormonal cross talk in insect development. Trends Endocrinol Metab 2005, 16:6-II.

44. Flatt T, Tu MP, Tatar M: Hormonal pleiotropy and the juvenile hormone regulation of Drosophila development and life history. Bioessays 2005, 27:999-1010.

45. Ashok M, Turner C, Wilson TG: Insect juvenile hormone resistance gene homology with the bHLH-PAS family of transcriptional regulators. Proc Natl Acad Sci USA 1998, 95:276I-2766.

46. Shemshedini L, Wilson TG: Resistance to juvenile hormone and an insect growth regulator in Drosophila is associated with an altered cytosolic juvenile hormone-binding protein. Proc Nat Acad Sci USA 1990, 87:2072-2076.

47. Miura K, Oda M, Makita S, Chinzei Y: Characterization of the Drosophila Methoprene-tolerant gene product. Juvenile hormone binding and ligand-dependent gene regulation. FEBS 2005, 272:1169-1178.

48. Kvint $K$, Nachin $L$, Diez A, Nystrom T: The bacterial universal stress protein: function and regulation. Curr Opin Microbiol 2003, 6:1 40-145

49. Boes N, Schreiber K, Hartig E, Jaensch L, Schobert M: The Pseudomonas aeruginosa universal stress protein PA4352 is essential for surviving anaerobic energy stress. J Bacteriol 2006, 188:6529-6538.

50. Schreiber K, Boes N, Eschbach M, Jaensch L, Wehland J, Bjarnsholt T, Givskov M, Hentzer M, Schobert M: Anaerobic survival of Pseudomonas aeruginosa by pyruvate fermentation requires an Usp-type stress protein. J Bacteriol 2006, I 88:659-668.

5I. Lawrenz MB, Miller VL: Comparative analysis of the regulation of rovA from the pathogenic yersiniae. J Bacteriol 2007, I 89:5963-5975.

52. Revell PA, Miller VL: A chromosomally encoded regulator is required for expression of the Yersinia enterocolitica inv gene and for virulence. Mol Microbiol 2000, 35:677-685.

53. Heroven AK, Dersch P: RovM, a novel LysR-type regulator of the virulence activator gene rovA, controls cell invasion, virulence and motility of Yersinia pseudotuberculosis. Mol Microbiol 2006, 62: 1469-1483.

54. Bochkareva ES, Girshovich AS, Bibi E: Identification and characterization of the Escherichia coli stress protein UP I 2, a putative in vivo substrate of GroEL. Eur J Biochem 2002, 269:3032-3040.

55. Kiser PD, Lodowski DT, Palczewski K: Purification, crystallization and structure determination of native GroEL from Escherichia coli lacking bound potassium ions. Acta Crystallograph Sect F Struct Biol Cryst Commun 2007, 63:457-461.

56. Cotter PA, Stibitz S: c-di-GMP-mediated regulation of virulence and biofilm formation. Curr Opin Microbiol 2007, 10:17-23.

57. Tamayo R, Pratt JT, Camilli A: Roles of Cyclic Diguanylate in the Regulation of Bacterial Pathogenesis. Annu Rev Microbiol 2007.

58. Jenal $U$, Malone J: Mechanisms of cyclic-di-GMP signaling in bacteria. Annu Rev Genet 2006, 40:385-407.

59. Pratt JT, Tamayo R, Tischler AD, Camilli A: PilZ domain proteins bind cyclic diguanylate and regulate diverse processes in Vibrio cholerae. I Biol Chem 2007, 282: I2860-12870.

60. Zogaj X, Nimtz M, Rohde M, Bokranz W, Romling U: The multicellular morphotypes of Salmonella typhimurium and Escherichia coli produce cellulose as the second component of the extracellular matrix. Mol Microbiol 200I, 39: 1452-1463.

6I. Bowen D, Rocheleau TA, Blackburn M, Andreev O, Golubeva E, Bhartia R, ffrench-Constant RH: Insecticidal toxins from the bacterium Photorhabdus luminescens. Science 1998, 280:2 129-2132.
62. Waterfield NR, Bowen DJ, Fetherston JD, Perry RD, ffrench-Constant $\mathrm{RH}$ : The tc genes of Photorhabdus: a growing family. Trends Microbiol 2001, 9:185-191.

63. Waterfield N, Hares M, Hinchliffe S, Wren B, ffrench-Constant R: The insect toxin complex of Yersinia. Adv Exp Med Biol 2007, 603:247-257.

64. Ratcliffe NA, Rowley AF: In vitro phagocytosis of bacteria by insect blood cells. Nature 1974, 252:391-392.

65. Jacob-Dubuisson F, Locht C, Antoine R: Two-partner secretion in Gram-negative bacteria: a thrifty, specific pathway for large virulence proteins. Mol Microbiol 200I, 40:306-3I3.

66. Fernandez L, Prieto M, Guijarro JA: The iron- and temperatureregulated haemolysin YhIA is a virulence factor of Yersinia ruckeri. Microbiology 2007, 153:483-489.

67. Bresolin G, Neuhaus K, Scherer S, Fuchs TM: Transcriptional analysis of long-term adaptation of Yersinia enterocolitica to lowtemperature growth. J Bacteriol 2006, I 88:2945-2958.

68. Vigneux F, Zumbihl R, Jubelin G, Ribeiro C, Poncet J, Baghdiguian S, Givaudan $A$, Brehelin M: The xaxAB genes encoding a new apoptotic toxin from the insect pathogen Xenorhabdus nematophila are present in plant and human pathogens. J Biol Chem 2007, 282:957I-9580.

69. Brown SE, Cao AT, Dobson P, Hines ER, Akhurst RJ, East PD: Txp40, a ubiquitous insecticidal toxin protein from Xenorhabdus and Photorhabdus bacteria. Appl Environ Microbiol 2006, 72: I653-1662.

70. Sha J, Kozlova EV, Chopra AK: Role of various enterotoxins in Aeromonas hydrophila-induced gastroenteritis: generation of enterotoxin gene-deficient mutants and evaluation of their enterotoxic activity. Infect Immun 2002, 70: 1924-1935.

71. Daborn PJ, Waterfield N, Silva CP, Au CP, Sharma S, ffrench-Constant RH: A single Photorhabdus gene, makes caterpillars floppy (mcf), allows Escherichia coli to persist within and kill insects. Proc Natl Acad Sci USA 2002, 99: 10742-10747.

72. Dowling AJ, Waterfield NR, Hares MC, Le Goff G, Streuli CH, ffrench-Constant RH: The Mcfl toxin induces apoptosis via the mitochondrial pathway and apoptosis is attenuated by mutation of the BH3-like domain. Cell Microbiol 2007, 9:2470-2484.

73. Waterfield NR, Daborn PJ, Dowling AJ, Yang G, Hares M, ffrenchConstant RH: The insecticidal toxin makes caterpillars floppy 2 (Mcf2) shows similarity to $\mathrm{HrmA}$, an avirulence protein from a plant pathogen. FEMS Microbiol Lett 2003, 229:265-270.

74. Parkhill j, Wren BW, Thomson NR, Titball RW, Holden MT, Prentice MB, Sebaihia M, James KD, Churcher C, Mungall KL, Baker S, Basham D, Bentley SD, Brooks K, Cerdeno-Tarraga AM, Chillingworth T, Cronin A, Davies RM, Davis P, Dougan G, Feltwell T, Hamlin N, Holroyd S, Jagels K, Karlyshev AV, Leather S, Moule S, Oyston PC, Quail M, Rutherford K, Simmonds M, Skelton J, Stevens K, Whitehead S, Barrell BG: Genome sequence of Yersinia pestis, the causative agent of plague. Nature 200I, 4I3:523-527.

75. Garcia-Calderon CB, Casadesus J, Ramos-Morales F: Rcs and PhoPQ Regulatory Overlap in the Control of Salmonella enterica Virulence. J Bacteriol 2007, 189:6635-6644.

76. Bohin JP: Osmoregulated periplasmic glucans in Proteobacteria. FEMS Microbiol Lett 2000, 186: I I-19.

77. Axler-Diperte GL, Miller VL, Darwin AJ: YtxR, a conserved LysRlike regulator that induces expression of genes encoding a putative ADP-ribosyltransferase toxin homologue in Yersinia enterocolitica. J Bacteriol 2006, 188:8033-8043.

78. Mikulskis AV, Delor I, Thi VH, Cornelis GR: Regulation of the Yersinia enterocolitica enterotoxin Yst gene. Influence of growth phase, temperature, osmolarity, $\mathrm{pH}$ and bacterial host factors. Mol Microbiol 1994, 14:905-915.

79. Waterfield NR, Wren BW, ffrench-Constant RH: Invertebrates as a source of emerging human pathogens. Nat Rev Microbiol 2004 , 2:833-84I.

80. Basset A, Tzou P, Lemaitre B, Boccard F: A single gene that promotes interaction of a phytopathogenic bacterium with its insect vector, Drosophila melanogaster. EMBO Rep 2003, 4:205-209.

8I. Held KG, Larock CN, D'Argenio DA, Berg CA, Collins CM: A metalloprotease secreted by the insect pathogen Photorhabdus luminescens induces melanization. Appl Environ Microbiol 2007.

82. Haller JC, Carlson S, Pederson KJ, Pierson DE: A chromosomally encoded type III secretion pathway in Yersinia enterocolitica is important in virulence. Mol Microbiol 2000, 36: I436-| 446. 
83. Gendlina I, Held KG, Bartra SS, Gallis BM, Doneanu CE, Goodlett DR, Plano GV, Collins CM: Identification and type III-dependent secretion of the Yersinia pestis insecticidal-like proteins. Mol Microbiol 2007, 64:1214-1227.

84. Young GM, Schmiel DH, Miller VL: A new pathway for the secretion of virulence factors by bacteria: the flagellar export apparatus functions as a protein-secretion system. Proc Nat Acad Sci USA 1999, 96:6456-6461.

85. Brugirard-Ricaud K, Givaudan A, Parkhill J, Boemare N, Kunst F, Zumbihl R, Duchaud E: Variation in the effectors of the type III secretion system among Photorhabdus species as revealed by genomic analysis. J Bacteriol 2004, | 86:4376-438|

86. Brugirard-Ricaud K, Duchaud E, Givaudan A, Girard PA, Kunst F, Boemare N, Brehelin M, Zumbihl R: Site-specific antiphagocytic function of the Photorhabdus luminescens type III secretion system during insect colonization. Cell Microbiol 2005, 7:363-37I.

87. Venecia K, Young GM: Environmental regulation and virulence attributes of the Ysa type III secretion system of Yersinia enterocolitica biovar IB. Infect Immun 2005, 73:596 I-5977.

88. Natale P, Bruser T, Driessen AJ: Sec- and Tat-mediated protein secretion across the bacterial cytoplasmic membrane-Distinct translocases and mechanisms. Biochim Biophys Acta 2007 in press.

89. Stathopoulos C, Hendrixson DR, Thanassi DG, Hultgren SJ, St Geme JW 3rd, Curtiss R 3rd: Secretion of virulence determinants by the general secretory pathway in gram-negative pathogens: an evolving story. Microbes Infect 2000, 2:106I-1072.

90. Iwobi A, Heesemann J, Garcia E, Igwe E, Noelting C, Rakin A: Novel virulence-associated type II secretion system unique to highpathogenicity Yersinia enterocolitica. Infect Immun 2003, 71:1872-1879.

91. Yahr TL: A critical new pathway for toxin secretion? $N$ Engl J Med 2006, 355: II7I-II72.

92. Pukatzki S, Ma AT, Sturtevant D, Krastins B, Sarracino D, Nelson WC, Heidelberg JF, Mekalanos JJ: Identification of a conserved bacterial protein secretion system in Vibrio cholerae using the Dictyostelium host model system. Proc Natl Acad Sci USA 2006, I03:1528-1533.

93. Mougous JD, Cuff ME, Raunser S, Shen A, Zhou M, Gifford CA, Goodman AL, Joachimiak G, Ordonez CL, Lory S, Walz T, Joachimiak A, Mekalanos Jl: A virulence locus of Pseudomonas aeruginosa encodes a protein secretion apparatus. Science 2006, 3 I 2: I526-1530.

94. Schmiel DH, Young GM, Miller VL: The Yersinia enterocolitica phospholipase gene ypIA is part of the flagellar regulon. J Bacteriol 2000, | 82:23|4-2320.

95. Hinnebusch BJ, Rudolph AE, Cherepanov P, Dixon JE, Schwan TG, Forsberg A: Role of Yersinia murine toxin in survival of Yersinia pestis in the midgut of the flea vector. Science 2002, 296:733-735.

96. Caldas C, Cherqui A, Pereira A, Simoes N: Purification and characterization of an extracellular protease from Xenorhabdus nematophila involved in insect immunosuppression. Appl Environ Microbiol 2002, 68: I 297-I304.

97. Silva CP, Waterfield NR, Daborn PJ, Dean P, Chilver T, Au CP, Sharma S, Potter U, Reynolds SE, ffrench-Constant RH: Bacterial infection of a model insect: Photorhabdus luminescens and Manduca sexta. Cell Microbiol 2002, 4:329-339.

98. Reddy SR, Campbell JW: Enzymic basis for the nutritional requirement of arginine in insects. Experientia 1977, 33:160-161.

99. Hensel M, Hinsley AP, Nikolaus T, Sawers G, Berks BC: The genetic basis of tetrathionate respiration in Salmonella typhimurium. Mol Microbiol I999, 32:275-287.

100. Price-Carter M, Tingey J, Bobik TA, Roth JR: The alternative electron acceptor tetrathionate supports B I 2-dependent anaerobic growth of Salmonella enterica serovar Typhimurium on ethanolamine or I,2-propanediol. J Bacteriol 2001, 1 83:2463-2475.

I0I. Korbel JO, Doerks T, Jensen LJ, Perez-Iratxeta C, Kaczanowski S, Hooper SD, Andrade MA, Bork P: Systematic association of genes to phenotypes by genome and literature mining. PLoS Biol 2005, 3: el 34 .
102. Klumpp J, Fuchs TM: Identification of novel genes in genomic islands that contribute to Salmonella typhimurium replication in macrophages. Microbiology 2007, I 53:1207-I 220.

103. Rakin A, Noelting C, Schubert S, Heesemann J: Common and specific characteristics of the high-pathogenicity island of Yersinia enterocolitica. Infect Immun 1999, 67:5265-5274.

104. Ciche TA, Blackburn M, Carney JR, Ensign JC: Photobactin: a catechol siderophore produced by Photorhabdus luminescens, an entomopathogen mutually associated with Heterorhabditis bacteriophora NCI nematodes. Appl Environ Microbiol 2003 69:4706-4713.

105. Crennell SJ, Tickler PM, Bowen DJ, ffrench-Constant RH: The predicted structure of photopexin from Photorhabdus shows the first haemopexin-like motif in prokaryotes. FEMS Microbiol Lett 2000, I9 I:139-|44.

106. ffrench-Constant RH, Waterfield N, Burland V, Perna NT, Daborn PJ, Bowen D, Blattner FR: A genomic sample sequence of the entomopathogenic bacterium Photorhabdus luminescens WI4: potential implications for virulence. Appl Environ Microbiol 2000 , 66:3310-3329.

107. Widenhorn KA, Somers JM, Kay WW: Expression of the divergent tricarboxylate transport operon (tctl) of Salmonella typhimurium. J Bacteriol 1988, I 70:3223-3227.

108. Sweet GD, Somers JM, Kay WW: Purification and properties of a citrate-binding transport component, the $\mathrm{C}$ protein of Salmonella typhimurium. Can J Biochem I979, 57:7 I0-7I5.

109. Sweet GD, Kay CM, Kay WW: Tricarboxylate-binding proteins of Salmonella typhimurium. Purification, crystallization, and physical properties. J Biol Chem 1984, 259:I586-I592.

I 10. Bott M: Anaerobic citrate metabolism and its regulation in enterobacteria. Arch Microbiol 1997, 167:78-88.

III. Camilli A, Mekalanos J]: Use of recombinase gene fusions to identify Vibrio cholerae genes induced during infection. Mol Microbiol 1995, | 8:67|-683.

I 12. Osorio CG, Crawford JA, Michalski J, Martinez-Wilson H, Kaper JB, Camilli A: Second-generation recombination-based in vivo expression technology for large-scale screening for Vibrio cholerae genes induced during infection of the mouse small intestine. Infect Immun 2005, 73:972-980.

I 13. Tchawa Yimga M, Leatham MP, Allen JH, Laux DC, Conway T, Cohen PS: Role of gluconeogenesis and the tricarboxylic acid cycle in the virulence of Salmonella enterica serovar Typhimurium in BALB/c mice. Infect Immun 2006, 74: I | 30- I | 40.

I14. Motin VL, Georgescu AM, Fitch JP, Gu PP, Nelson DO, Mabery SL, Garnham JB, Sokhansanj BA, Ott LL, Coleman MA, Elliott JM, Kegelmeyer LM, Wyrobek AJ, Slezak TR, Brubaker RR, Garcia E: Temporal global changes in gene expression during temperature transition in Yersinia pestis. I Bacteriol 2004, | 86:6298-6305

II5. Gort AS, Miller VL: Identification and characterization of Yersinia enterocolitica genes induced during systemic infection. Infect Immun 2000, 68:6633-6642.

II6. Straley SC, Perry RD: Environmental modulation of gene expression and pathogenesis in Yersinia. Trends Microbiol 1995 , 3:310-317.

II7. Young GM, Badger JL, Miller VL: Motility is required to initiate host cell invasion by Yersinia enterocolitica. Infect Immun 2000 , 68:4323-4326.

I 18. Bleves S, Marenne MN, Detry G, Cornelis GR: Up-regulation of the Yersinia enterocolitica yop regulon by deletion of the flagellum master operon flhDC. J Bacteriol 2002, I 84:32| 4-3223.

119. Cowles KN, Goodrich-Blair $\mathrm{H}$ : Expression and activity of a Xenorhabdus nematophila haemolysin required for full virulence towards Manduca sexta insects. Cell Microbiol 2005 , 7:209-219.

120. Bresolin G, Trcek J, Scherer S, Fuchs TM: Presence of a functional flagellar cluster Flag-2 and low-temperature expression of flagellar genes in Yersinia enterocolitica W22703. Microbiology 2008, I 54:196-206.

I2I. Waterfield NR, Daborn PJ, ffrench-Constant RH: Genomic islands in Photorhabdus. Trends Microbiol 2002, 1 0:54I-545.

122. Maier RJ: Use of molecular hydrogen as an energy substrate by human pathogenic bacteria. Biochem Soc Trans 2005, 33:83-85

123. Derzelle S, Turlin E, Duchaud E, Pages S, Kunst F, Givaudan A Danchin A: The PhoP-PhoQ two-component regulatory sys- 
tem of Photorhabdus luminescens is essential for virulence in insects. J Bacteriol 2004, 186: I270-1279.

124. Goodrich-Blair H, Clarke DJ: Mutualism and pathogenesis in Xenorhabdus and Photorhabdus: two roads to the same destination. Mol Microbiol 2007, 64:260-268.

125. Carver TJ, Rutherford KM, Berriman M, Rajandream MA, Barrell BG, Parkhill J: ACT: the Artemis Comparison Tool. Bioinformatics 2005, $21: 3422-3423$.

126. Kuenne CT, Ghai R, Chakraborty T, Hain T: GECO - linear visualization for comparative genomics. Bioinformatics 2007, 23:125-126.

127. Geer LY, Domrachev M, Lipman DJ, Bryant SH: CDART: protein homology by domain architecture. Genome Res 2002, 12:1619-1623.

128. Letunic I, Copley RR, Schmidt S, Ciccarelli FD, Doerks T, Schultz J, Ponting CP, Bork P: SMART 4.0: towards genomic data integration. Nucleic Acids Res 2004, 32:D I 42-I 44.

129. Finn RD, Mistry J, Schuster-Bockler B, Griffiths-Jones S, Hollich V, Lassmann T, Moxon S, Marshall M, Khanna A, Durbin R, Eddy SR, Sonnhammer EL, Bateman A: Pfam: clans, web tools and services. Nucleic Acids Res 2006, 34:D247-25I.

130. Niskanen T, Waldenstrom J, Fredriksson-Ahomaa M, Olsen B, Korkeala $\mathrm{H}$ : virF-positive Yersinia pseudotuberculosis and Yersinia enterocolitica found in migratory birds in Sweden. Appl Environ Microbiol 2003, 69:4670-4675.

131. Raffa RG, Raivio TL: A third envelope stress signal transduction pathway in Escherichia coli. Mol Microbiol 2002, 45:1599-161I.

132. Baker MD, Wolanin PM, Stock JB: Signal transduction in bacterial chemotaxis. Bioessays 2006, 28:9-22.

133. Kocan M, Schaffer S, Ishige T, Sorger-Herrmann U, Wendisch VF, Bott M: Two-component systems of Corynebacterium glutamicum: deletion analysis and involvement of the PhoS-PhoR system in the phosphate starvation response. J Bacteriol 2006, 188:724-732.

134. Verhamme DT, Arents JC, Postma PW, Crielaard W, Hellingwerf KJ: Glucose-6-phosphate-dependent phosphoryl flow through the Uhp two-component regulatory system. Microbiology 200I, 147:3345-3352.

135. Gunsalus RP, Park SJ: Aerobic-anaerobic gene regulation in Escherichia coli: control by the ArcAB and Fnr regulons. Res Microbiol 1994, 145:437-450.

136. Mondragon V, Franco B, Jonas K, Suzuki K, Romeo T, Melefors O, Georgellis D: pH-dependent activation of the BarA-UvrY twocomponent system in Escherichia coli. J Bacteriol 2006 1 88:8303-8306.

137. Erickson KD, Detweiler CS: The Rcs phosphorelay system is specific to enteric pathogens/commensals and activates ydel, a gene important for persistent Salmonella infection of mice. Mol Microbiol 2006, 62:883-894.

138. Jung K, Altendorf K: Towards an understanding of the molecular mechanisms of stimulus perception and signal transduction by the KdpD/KdpE system of Escherichia coli. J Mol Microbiol Biotechnol 2002, 4:223-228.

139. Jung K, Hamann K, Revermann A: $\mathbf{K}^{+}$stimulates specifically the autokinase activity of purified and reconstituted EnvZ of Escherichia coli. I Biol Chem 200I, 276:40896-40902.

140. Martinez-Argudo I, Martin-Nieto J, Salinas P, Maldonado R, Drummond $M$, Contreras $A$ : Two-hybrid analysis of domain interactions involving $\mathrm{NtrB}$ and $\mathrm{NtrC}$ two-component regulators. Mol Microbiol 200I, 40:169-178.

14l. Bijlsma JJ, Groisman EA: The PhoP/PhoQ system controls the intramacrophage type three secretion system of Salmonella enterica. Mol Microbiol 2005, 57:85-96.

142. Beier D, Gross R: Regulation of bacterial virulence by twocomponent systems. Curr Opin Microbiol 2006, 9:143-152.

143. Majdalani N, Gottesman S: The Rcs phosphorelay: a complex signal transduction system. Annu Rev Microbiol 2005, 59:379-405.

144. Mouslim C, Delgado M, Groisman EA: Activation of the RcsC/ YojN/RcsB phosphorelay system attenuates Salmonella virulence. Mol Microbiol 2004, 54:386-395.

145. Brunskill EW, Bayles KW: Identification of LytSR-regulated genes from Staphylococcus aureus. I Bacteriol 1996, i 78:5810-58I2.

146. Kaspar S, Bott M: The sensor kinase CitA (DpiB) of Escherichia coli functions as a high-affinity citrate receptor. Arch Microbiol 2002, |77:3|3-32|.
147. Skurnik M, Toivanen P: Yersinia enterocolitica lipopolysaccharide: genetics and virulence. Trends Microbiol 1993, I:I48-152.

148. de Koning-Ward TF, Robins-Browne RM: A novel mechanism of urease regulation in Yersinia enterocolitica. FEMS Microbiol Lett 1997, 147:221-226

149. Han Y, Zhou D, Pang X, Song Y, Zhang L, Bao J, Tong Z, Wang J, Guo $Z$, Zhai J, Du Z, Wang X, Zhang X, Wang J, Huang P, Yang R: Microarray analysis of temperature-induced transcriptome of Yersinia pestis. Microbiol Immunol 2004, 48:79|-805.

150. Perry RD, Bobrov AG, Kirillina O, Jones HA, Pedersen L, Abney J, Fetherston JD: Temperature regulation of the hemin storage $\left(\mathrm{Hms}^{+}\right.$) phenotype of Yersinia pestis is posttranscriptional. J Bacteriol 2004, 186:1638-1647.

15I. Perry RD: Acquisition and storage of inorganic iron and hemin by the yersiniae. Trends Microbiol 1993, I:I42-147.

152. Fernandez L, Marquez I, Guijarro JA: Identification of specific in vivo-induced (ivi) genes in Yersinia ruckeri and analysis of ruckerbactin, a catecholate siderophore iron acquisition system. Appl Environ Microbiol 2004, 70:5199-5207.

153. Isberg RR, Swain A, Falkow S: Analysis of expression and thermoregulation of the Yersinia pseudotuberculosis inv gene with hybrid proteins. Infect Immun 1988, 56:2133-2I38.

154. Cabral CM, Cherqui A, Pereira A, Simoes N: Purification and characterization of two distinct metalloproteases secreted by the entomopathogenic bacterium Photorhabdus sp. strain Az29. Appl Environ Microbiol 2004, 70:383I-3838.
Publish with BioMed Central and every scientist can read your work free of charge

"BioMed Central will be the most significant development for disseminating the results of biomedical research in our lifetime. "

Sir Paul Nurse, Cancer Research UK

Your research papers will be:

- available free of charge to the entire biomedical community

- peer reviewed and published immediately upon acceptance

- cited in PubMed and archived on PubMed Central

- yours - you keep the copyright

Submit your manuscript here:

http://www.biomedcentral.com/info/publishing_adv.asp
BioMedcentral 